\title{
Early prosocial development: a systematic review of evidence to support the integration of neurocognitive and cross cultural methods
}

\author{
Laura Katus, Gabrielle McHarg, Claire Hughes \\ Centre for Family Research, Department of Psychology, University of Cambridge \\ Corresponding Author: Laura Katus, Centre for Family Research, Free School Lane, Cambridge CB2 3QR, \\ Ik466@cam.ac.uk
}

Word count main text: 9,113

Highlights [3-5, 85 characters including spaces]

- Prosocial development is increasingly studied behaviourally across cultures [77]

- Neuroimaging/eye tracking can measure underlying processes of prosocial behaviour [83]

- Neurocognitive methods can help standardise assessments across sites [71]

- Literature from western settings describes paradigms with cross-cultural utility [82]

- A longitudinal, multi-site implementation of neurocognitive methods is proposed [81]

\begin{abstract}
Introduction. Within the relatively young field of social neuroscience, there is growing interest in the interplay between biological and social influences on early prosociality (which includes key constructs of helping, sharing and comforting). In particular, neuroimaging (electroencephalography [EEG], functional near infrared spectroscopy [fNIRS]) and eye tracking haven proven invaluable methods to study infants and young children. These measures are more easily adapted for use in different cultural settings than many behavioural paradigms and so hold great potential for implementation in crosscultural research. Method. We conducted two searches of studies of prosocial development during infancy and early childhood, one with a focus on recent methodological advances and one to review studies in low- and middle-income countries (LMICS) over the past 20 years. Results. In total, we identified 15 studies that used neurocognitive methods; these had a strong focus on helping behaviour and conducted almost exclusively in high-income settings. We also identified 20 studies that investigated prosocial development in LMICs; these focussed primarily on sharing, and included just two eye-tracking studies and no studies using either EEG or fNIRS. Discussion. Several directions for future research emerged from this review. These include the need for: (i) longitudinal research to elucidate developmental trajectories; (ii) investigations involving young infants ( $<12$ months); and (iii) the potential importance of applying EEG, fNIRS and eye tracking in cross cultural research into prosocial development.
\end{abstract}

Keywords [up to 6] prosocial behaviour, neuroimaging, eye tracking, neurodevelopment, LMIC, crosscultural 


\section{Introduction}

The development of prosocial behaviour (i.e. actions that benefit a social partner, rather than the individual displaying them), is a fundamental capacity that emerges in infancy, with potential to affect social interactions across the life span. In his classic study of emotion expression, Darwin (1872) noted that facial and body expressions play a crucial role in infants' social development, providing "a first means of communication between the mother and her infant: she smiles approval and thus encourages her child on the right path, or frowns disapproval" (pp.365-366). Following in Darwin's footsteps, other theorists (e.g., Tomasello, 2000) have argued that the ability to understand and cooperate with others is crucial to the global success of our species. While recent years have seen increasing interest in understanding how prosocial behaviours first develop in infants and young children (Brownell, 2013; Paulus, 2014), these studies are biased by a focus on western, educated, industrialised, rich and democratic (WEIRD, Henrich, Heine \& Norenzayan, 2010) countries. This lack of diversity restricts conclusions on the universality of prosocial behaviours and their developmental trajectories (Margoni \& Surian, 2018). In this systematic review we first aim to describe how neurocognitive methods (specifically electroencephalography [EEG], functional near infrared spectroscopy [fNIRS] and eye tracking) underpin recent advances in the study of prosocial development (primarily focussing on helping, sharing and comforting). Our second aim is to examine evidence on prosocial development gathered in low and middle-income countries (LMICs). Combining these two strands of research, we conclude by discussing how one might apply neurocognitive methodology to cross-cultural research to enable more objective, longitudinal measurements of prosocial development from infancy.

\section{The development of prosocial behaviours in infants and young children}

Even before overtly displaying prosocial behaviours, infants lay the groundwork for prosocial acts. Heyes (2018) asserts infants are associating emotions and reactions, which become the building blocks for empathy and empathic responding. In addition, social interactions in infancy provide vital experience for later prosocial behaviour (e.g., Heyes, 2018). For example, infants as young as three months of age display greater attention to agents who display prosocial rather than antisocial behaviour, and show an aversion to antisocial agents (Kuhlmeier, Wynn \& Bloom, 2003; Hamlin, Wynn \& Bloom, 2007; Hamlin \& Wynn, 2011; Hamlin Wynn Bloom, 2010). These attentional biases are thought to represent a prosocial preference, which also expressed behaviourally. Infants' reach for actors who exhibit prosocial versus antisocial actions more frequently, even when controlling for perceptual differences between pro-and antisocial scenarios (i.e. helping vs hindering, Hamlin, 2015). Approximately two thirds of 4-32 month old infants, consistently display this phenomenon (Margoni \& Surian, 2018). Infants' differential responses to pro- and antisocial actions not only depends on the 
agent, but also on recipient characteristics. While five month old infants differentially attend to characters who, intentionally or unintentionally, behave in a prosocial way, eight month old infants only showed this preference when an agent displayed intentional prosocial behaviour (Hamlin, 2013), suggesting an element of social evaluation. Further support for a social evaluation account stems from the finding that infants also preferentially attend to individuals who behave negatively toward an antisocial agent (Hamlin, Wynn, Bloom, Mahajan, 2011). From around 12 months, infants start to form a default expectation for prosocial behaviour (i.e. fair behaviour in sharing scenarios, Sloane, Baillargeon \& Premack, 2012).

Differential trajectories. Some evidence suggests that helping, sharing and comforting develop across different timescales (Kärtner, Schumacher, \& Collard, 2014, Paulus, 2014; Dunfield et al., 2011). These differences may reflect domain-general developmental gains in memory, processing speed, and attention (Hamlin, 2014). Overt helping behaviours are first observed around 14 months of age, even though some parent report measures may indicate an earlier onset (Hammond et al., 2018). Warneken and Tomasello (2007) found that three quarters of 14-month-old children helped at least once in a battery of help-eliciting tasks and, using a similar battery, Schuhmacher, Collard, and Kärtner (2017) found that nearly all 18 month old children helped at least once. Older children also appear more selective in their helping (i.e. more sensitive to recipient characteristics, Malti et al., 2016). Sharing behaviour is typically observed to increase from early to middle childhood resulting in fairer resource allocation with increasing age (Gummerum et al., 2010; Benenson, Pascoe \& Radmore, 2007; Fehr, Bernhard \& Rockenbach, 2008). Empathic responding - comforting and helping behaviours intended to alleviate another's distress (Eisenberg et al., 2006) also emerge in the second year of life (e.g., Moreno, Klute \& Robinson, 2008). This relatively late onset reflects the fact that comforting behaviours require several advanced skills, including the recognition of distress signals, as well as the awareness that the distress belongs to the other rather than the self (e.g., Kärtner, Keller, \& Chaudhary, 2010).

Observing versus enacting prosocial behaviours. While many studies with older infants and children rely on the observation of overt prosocial behaviours, studies with younger infants frequently measure attention allocation towards pro- versus antisocial agents or scenarios. The same is true for studies employing neurocognitive methodology, as these frequently rely on passive observation by the participant. In context of this review, we will consider both active and passive indices of prosociality, for two reasons. First, the lack of reliance on overt behaviours in neurodevelopmental research is a strength in cross-cultural contexts, as it bridges differences in familiarity with object play, or one to one interaction with an experimenter that may exist across cultures. Further, it enables measurement of infants' who are not yet motorically advanced enough to enact these behaviours 
themselves. Second, early attentional biases hold predictive validity for both concurrent and longitudinal prosocial behaviour. Infants' increased attention allocation to pro-vs anti-social agents is associated with their increased likelihood of sharing a toy with a peer, indicating a behavioural manifestation of a cognitive preference (Schmidt \& Sommerville, 2011).

\section{Individual differences in early prosocial behaviour}

Alongside rapid developmental change, young children also show striking individual differences in the frequency and context of their prosocial behaviour (Paulus, 2014), the sources of which could be elucidated further by cross-cultural designs. It is worth noting that although aspects of prosocial behaviour such as empathy are often viewed as a universal good (e.g. Zaki, 2018), thinkers as far back as Plato have argued that morality should be guided by principles rather than passions (Moss, 2012). From this perspective, empathy can also be viewed as a potential source of irrational thinking and ingroup bias (e.g. Bloom, 2017). Equally, sharing behaviours may indicate a desire to conform to cultural norms or by the anticipation of reciprocal sharing in the future and so are not necessarily as altruistic as they first appear. These theoretical debates however fall outside the scope of the current review, given our focus on methodology.

Origins of individual differences in prosocial behaviour. There are three conceptual camps with regards to the origins of individual differences in prosocial behaviour. Nativist accounts (e.g., Hamlin, 2014) emphasize the ancient nature of social brain mechanisms within bird and mammalian evolution and attribute individual differences to genetically influenced biological mechanisms (e.g., oxytocin release, Pedersen, Chang \& Williams, 2014). Others argue that behaviours such as sharing, helping and comforting are rooted in social interaction (e.g., Brownell et al., 2013), such that exposure to callous behaviour has the power to undermine empathy (Heyes, 2018). Bridging these two competing views, others have proposed hybrid accounts that integrate biological mechanisms with the impact of exposure to supportive or adverse social environments (Knafo-Noam, Vertsberger \& Israel, 2018).

As noted above, 'prosocial behaviour' is not a unitary concept but rather an umbrella term, encompassing a variety of actions (most notably, sharing, helping and comforting, Dunfield, 2014; Paulus, 2014). As a result, the relative salience of nature and nurture may differ for individual differences each of these components. To address this possibility, Knafo-Noam, et al. (2018) conducted an re-analysis of data from an experimental study of 152 pairs of 3.5 year old twins, which involved six situations designed to elicit sharing, helping and comforting (Knafo, Israel \& Ebstein, 2011). Their findings, illustrated in Figure 1, showed marked differences in heritability, which appeared negligible for individual differences in helping, modest for individual differences in sharing and substantial for individual differences in comforting. 

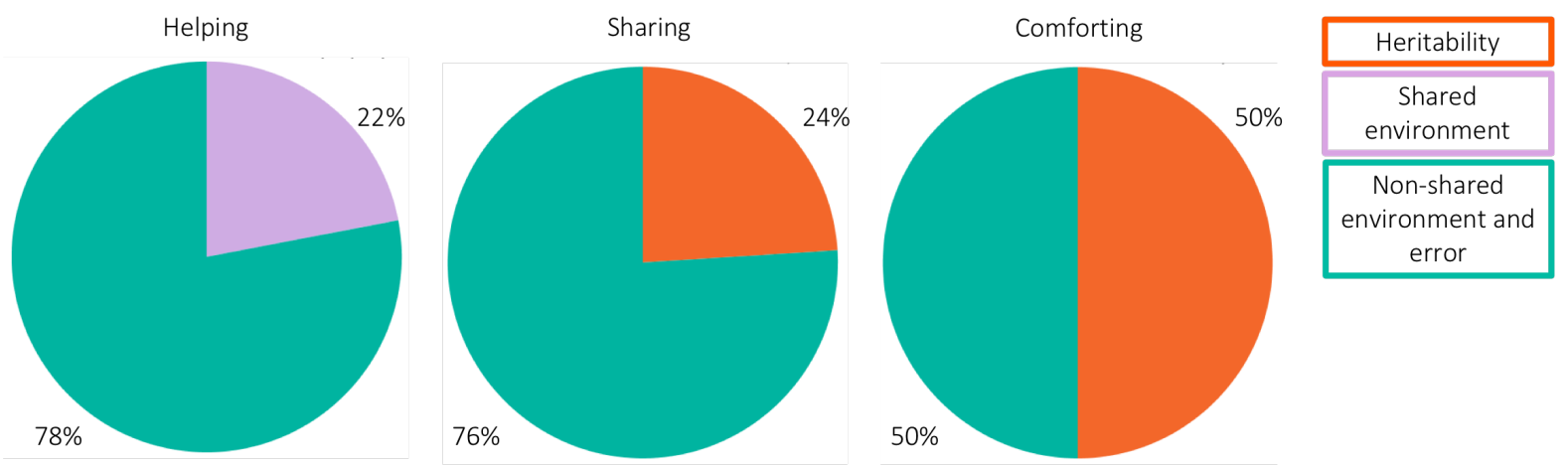

Figure 1. Adapted from Knafo-Noam et al., 2018. Genetic and environmental variance component estimates in different prosocial behaviours.

Molecular genetic studies of prosocial behaviour / morality have, to date, largely focused on adults (for a review, see Israel et al., 2015), although some evidence indicates that genes in the oxytocinvasopressin system underpin individual differences in helping and comforting (Wu \& Su, 2015). Support for this view comes from meta-analytic findings measures of sociality are associated with polymorphism in the oxytocin receptor gene OXTR (rs53576). However, candidate gene studies have received considerable criticism for several reasons (e.g., small samples, lack of replication and a failure to control for variation in allelic frequencies in subsamples of different ancestry) and are increasingly replaced by genome wide association studies. This approach has indicated that genetic variation across the genome accounts for $12 \%$ of variation in self-reported empathy (Warrier et al, 2016), substantially lower than the 50\% indicated in Figure 1.

Interactions between genetic and environmental influences. A simple explanation for this contrast is the likely interaction between genetic and environmental effects. For example, heritability estimates for prosocial behaviour appear much lower for twins who have other siblings than for twins without other siblings (Knafo \& Israel, 2009). Likewise in a study in a sample of Nigerian adolescent twins, Hur, Taylor, Jeong, Park and Haberstick (2017) showed that family cohesiveness amplified environmental influences on prosocial behaviour. A similar amplifying effect on the size of young school-aged children's friendship (Rivizzigno, Brendgen, Feng, Vitaro, Dionne, Tremblay, \& Boivin, 2014) provides converging evidence that the number and quality of children's social relationships moderates the impact of genetic influences on prosociality. Adding complexity to the picture, however, children also play an active role in selecting their environments, such that effects that appear environmental may be at least partly mediated by genetic factors, offering a possible explanation for the observed agerelated increase in the heritability of prosocial behaviour (Beam \& Turkheimer, 2013).

\section{Cross cultural perspectives on prosocial development}


Cross-cultural paradigms can offer key insights into children's prosocial tendencies (Köster,

Schuhmacher, \& Kärtner, 2015), and hold potential to further disentangle the interaction of genetic and environmental factors discussed above. Developmental differences in prosocial behaviour have been examined in the context of numerous socio-cultural factors, including cultural attitudes towards child development, endorsement of individualist vs collectivist norms, subsistence strategies, geographical location and urbanisation. Building on a large body of observational studies highlighting cross-cultural differences in prosocial development (Borke, 1973; Haidt, Koller \& Dias, 1993; Wainryb, 1995), the cognitive and socio-emotional mechanisms underlying those differences have received increased attention over recent years (Cowell et al., 2017). This work has shown that an integration of associated cognitive processes (i.e. assessing abilities to delay gratification and plan ahead in context of reciprocal sharing) could provide a valuable addition to understand the mechanisms underlying prosociality across cultures (Callaghan \& Corbit, 2018).

Both early social biases (i.e. social attention, Callaghan et al., 2011) and domain-general developmental processes play a role in the emergence of prosocial behaviour, and are both affected by cultural factors (Lan, Legare, Ponitz, Li, \& Morrison, 2011; Sabbagh, Xu, Carlson, Moses, \& Lee, 2006). While researchers typically attribute universal importance to certain influences on prosocial development (i.e. maternal encouragement and structuring of opportunities for prosocial behaviour), the expressions of these enabling factors may be culture-specific. For example, Köster and colleagues (2016) reported that mothers from Brazil and Germany adopted different scaffolding styles with their children, but that adoption of the prevalent style in one's community led to the highest levels of prosocial behaviours in children in either setting. Given this interplay of culturally specific and universal factors, the question of whether inter- or intra-cultural differences are associated with greater variance in timing and emergence of prosocial behaviours remains a topic of debate (Safra et al., 2016, Korndörfer et al., 2015).

\section{Neural correlates of prosocial behaviour}

Neuroscience has contributed in several key ways to our understanding of processes underpinning developmental change in prosociality. For example, there is broad support for two domain-general mechanisms: attention allocation (or experience sharing) and emotional evaluation and regulation (or mentalizing). Across the first year of life, attention allocation is evident very early, while the complex systems of emotional evaluation and regulation emerge more gradually. As children grow up, these neural systems are differentially recruited in distinct situations. In particular, prosocial responses to the incidental witnessing of others' pain or delight are linked to 'neural resonance' (i.e., the engagement of corresponding neural structures). In contrast, helping behaviour is associated with the activation of areas associated with mentalizing (especially medial prefrontal cortex) when individuals 
are explicitly asked to consider others' mental states (e.g., Zaki \& Ochsner, 2012). In a review of the social brain in adult psychiatric disorders, Kennedy and Adolphs (2012) offer a more elaborated taxonomy of neural systems underpinning the processing of social information that distinguishes four major social processing networks:

The Amygdala network (amygdala and orbito-frontal regions) is involved in threat detection, emotional evaluation and emotion regulation.

The Mentalizing network (medial prefrontal and superior temporal regions) is implicated in the automatic attribution of mental states.

The Empathy network (insula and amygdala regions) is involved in detecting and responding emotionally to others' distress.

The Mirror network (parietal and prefrontal regions) is responsive to both observed and executed actions.

Yet, it is not clear how this four-part division of social information processing emerges on a developmental time-scale. For theorists who emphasize the ancient nature of social mechanisms in the brain, (e.g., de Waal and Preston, 2017), developmental processes are maturational (e.g., improved efficiency of information transfer across brain regions resulting from increased connectivity - Hoff, Van Den Heuvel, Benders, Kersbergen \& de Vries, 2013). However, other theorists (e.g., Johnson et al., 2014; Heyes, 2018) have argued for the importance of learning processes (e.g., associative matching).

The potential of neurocognitive methods to study prosocial development. How might developmental neuroscience advance our understanding of early prosocial development? Addressing this question in a recent review, Cowell, Calma-Birling and Decety (2018) argued that, although their correlational nature constrains causal conclusions, neural measures offer a new and important means of testing extant theories.

In particular, electrophysiological measures do not require individuals to keep completely still during data acquisition and so provide an elegant means of quantifying neural activity in young children. Below we provide a concise overview of three methodologies (EEG, fNIRS and eye tracking) that can be used longitudinally from birth, which have advanced our understanding of early prosociality (Steinbeis, 2018). First, EEG has provided valuable insights into neurodevelopment in two ways: by extracting event related potentials (ERPs), which provide precise temporal information on both rapid, automatic processes and slower cognitively controlled systems; and by examining continuous changes in specific frequency bands in the EEG. Second, fNIRS has the potential to inform our understanding of spatially localised neural activation associated with prosocial development. Third, eye tracking has gained traction in the study of early prosocial behaviour. Though not a direct measure of neural activation, eye tracking can yield insights into processes of rapid attention allocation and sustained 
attention (for example to a helping vs hindering scenario, Hinten, Labuschange, Boden, Scarf \& 2018) over time.

Potential of neurocognitive methods in cross-cultural research. EEG, fNIRS and eye tracking can offer mechanistic evidence, as they can inform underlying attentional (eye tracking) and neural processes (EEG, fNIRS) of prosocial development. Over the past years, technological advances have yielded highly portable EEG, fNIRS and eye tracking hardware, enabling studies in the home or even in remote, rural regions of the world (Katus et al., 2019; Blasi, Lloyd-Fox, Katus \& Elwell, 2019). These methods provide a high degree of objectivity, frequently relying on passive audio-visual stimulation, which either are non-culturally specific or else can be more easily adjusted to fit cultures than standardised behavioural assessments. This leads to a high degree of standardisation across sites, enabling multi-cultural set ups.

EEG / ERP. First implemented in the 1930s (Lindsley, 1939), electrophysiological measures have a long-standing tradition in infant research. EEG recordings offer an excellent temporal resolution ( 1ms) or electrical changes or cortical neurons. One of the most common modes of analysis for EEG measures in developmental research lies in the extraction of ERPs. These represent changes within the EEG, which are time-locked to a stimulus in response and averaged across many trials. Due to the rapid stimulus presentation (approximately 1 trial per 1-3 seconds), many trials can be presented in short amount of time increasing the signal to noise ratio. Resulting waveforms are then analysed in terms of magnitude of negative and positive deflections. Across all cognitive domains, there exists a vast literature on associated ERP components, measured in different populations, and across development for many cognitive domains, making ERPs a good candidate measure for use in novel, previously understudied populations. Further, EEG can provide changes in activation (or power) across different oscillatory frequencies, which can be associated with different cognitive functions. In contrast to ERPs, power-based- based measured can be obtained in resting state designs in absence of stimulation. Secondly, task-related power changes can yield additional insights into the underlying neural mechanisms across cognitive domains.

fNIRS. Over the past decade, fNIRS has emerged as a means to measure spatially localised changes in cortical activation in infants and young children (Lloyd-Fox, Blasi \& Elwell, 2010). fNIRS measures the haemodynamic response that occurs as a consequence of neural activation. As neurons in a specific brain region activate, blood flow to this region increases, leading to an increase in oxygenated blood, as well as a washout of deoxygenated blood over the area of activation. As near infrared light is differentially absorbed by oxy- and deoxygenated blood, these changes are measured via the degree to which near infrared light is absorbed. This is achieved by placing light emitting sources and light sensitive detectors on participants' heads. Via placement of multiple source-detector pairs on 
participants' scalp, localised changes in oxy- and deoxy-haemoglobin can be measured, providing a secondary measure of neuronal activation.

Eye tracking. Looking time measures have a long-standing tradition in developmental research (see Oakes, 2012). Eye tracking offers a way to automatically quantify looking behaviours with high temporal and spatial resolution, leading to the suggestions that the use of eye tracking should be the rule, rather than the exception in visual developmental studies (Hinten et al., 2018). Measures can be extracted on 1) visual search strategies, 2) time to detect a visual target, 3) reaction times associated with engagement/ disengagement with a salient stimulus, 4) looking time decrements over time, indicating habituation. As reviewed in Grossmann (2018), another promising avenue for eye tracking research in the study of prosocial behaviour lies in pupillometry, thus changes in pupil dilation in response to a stimulus, which provides and indicator of changes in participants' arousal state. In summary, EEG, fNIRS and eye tracking lend themselves to the longitudinal study of infants/children across settings/cultures, as well as in context of early adversity, therefore making them well-suited for global neurodevelopmental research.

\section{Aims of the current review}

Building on the current knowledge base, our first aim is to review the recent evidence using neurocognitive measured to study early prosocial development. Our second aim is to summarise findings on prosocial development obtained in LMICs. Our third aim is to assess in how far studies in LMIC settings already implementing neurocognitive methods.

\section{Method}

Search Strategy. We performed two searches (Table 1). The first search served to identify publications using either neuroimaging or eye tracking methods to investigate the development of prosocial behaviours (Method search). We included relevant terms to describe prosocial behaviours, as well as search terms referring to developmental studies. The search for neurocognitive methods was limited to those most commonly used in infants and young children, specifically EEG, fNIRS, eye tracking, as well as related terms referring to specific modes of analysis for each of these methods (i.e. eventrelated potentials for EEG, diffuse optical imaging as an alternative descriptor for fNIRS). Due to their limited utility for use with developing populations as well as their limited availability in/portability to rural settings other neuroimaging methods were not specifically included as search terms. Our second search was aimed at identifying publications describing studies into the development of prosocial behaviours in LMICs (LMIC search). Again, we included search terms related to prosocial behaviour and development but not the term to describe specific neurocognitive methodology. Instead, we included a set of search terms to limit the search to LMICs. 
For both searches, search and relevant MeSH terms (Table 1) were entered into SCOPUS, EMBASE, Pubmed and PsychInfo. To obtain the broadest overview of available methods, reports on both typically developing and clinical populations were considered. Results were limited to empirical studies, performed on human participants and published in English. Both searches were performed in October 2019. In addition to the database searches, we manually searched for relevant reports among recent publications by authors in the field. We further screened the references of all included reports to identify further relevant records.

Table 1. Search Strategy for both searches.

\begin{tabular}{|c|c|}
\hline $\begin{array}{l}\text { Search \#1 } \\
\text { [prosocial] }\end{array}$ & 'prosocial' OR 'help*' OR 'shar*' OR 'comfort*' OR 'empath*' OR 'cooperat*' \\
\hline $\begin{array}{l}\text { Search \#2 } \\
\text { [development] }\end{array}$ & 'child*' OR 'preschool*' OR 'infan*' OR 'toddler*' \\
\hline $\begin{array}{l}\text { Search \#3 } \\
\text { [methods] }\end{array}$ & $\begin{array}{l}\text { 'neuroimaging' OR 'brain imaging' OR 'electroencephalogra*' OR 'EEG OR } \\
\text { 'event related potential*' OR 'ERP' OR 'electrophysiolog*' OR 'eye tracking' OR } \\
\text { 'gaze' OR 'near infrared spectroscopy' OR 'NIRS' OR 'fNIRS' OR 'diffuse optical imaging' } \\
\text { OR 'diffuse optical tomography' }\end{array}$ \\
\hline $\begin{array}{l}\text { Search \#4 } \\
\text { [LMIC] }\end{array}$ & 'low- and middle-income' OR 'low-income' OR 'middle-income' OR 'LMIC' \\
\hline Method search & Search \#1 AND Search \#2 AND Search \#3 \\
\hline LMIC search & Search \#1 AND Search \#2 AND Search \#4 \\
\hline
\end{tabular}

Selection Criteria (eligibility). For the Method search, publications were included if they 1 ) were published in the last 5 years from the search date (2014 - present), 2) described studies in children younger than 5 years of age, 3 ) used the relevant methodology to study prosocial development. Due to the relative scarcity of research in this area, inclusion criteria for the search for the LMIC search were set to be more lenient, in order to identify any relevant records. Specifically, we included any papers published 1) in the last 20 years, 2) examined all ages between 0-10 years of age, 3) were conducted using either behavioural observation, questionnaire measures or neurocognitive methods to study prosocial development. For both searches, reports describing age groups that went beyond the stipulated ranges were included, however our discussion was primarily focused on our specified age ranges. 
Study selection. Titles were screened by the first author (LK) to exclude irrelevant results. The abstracts of included reports were then scanned by two of the authors (GMcH, LK) who independently created lists of relevant reports. Reliability between these ratings was high (Cronbach's $\left.\alpha_{\text {Method }}=.853, \alpha_{L M I C}=.907\right)$. Any disagreements were resolved by discussion between both raters in reference to the full-text reports.

\section{Results}

Method search. In total, $N=751$ records were identified once duplicates were discarded. Of these, $N$ $=678$ were discarded as clearly irrelevant, leaving $N=75$ abstracts to screen against our inclusion criteria. For this search, $N=12$ records were eligible, the references of which were screened to identify additional records. In total, $N=15$ reports were included for this search. The search process is illustrated in Figure 2.

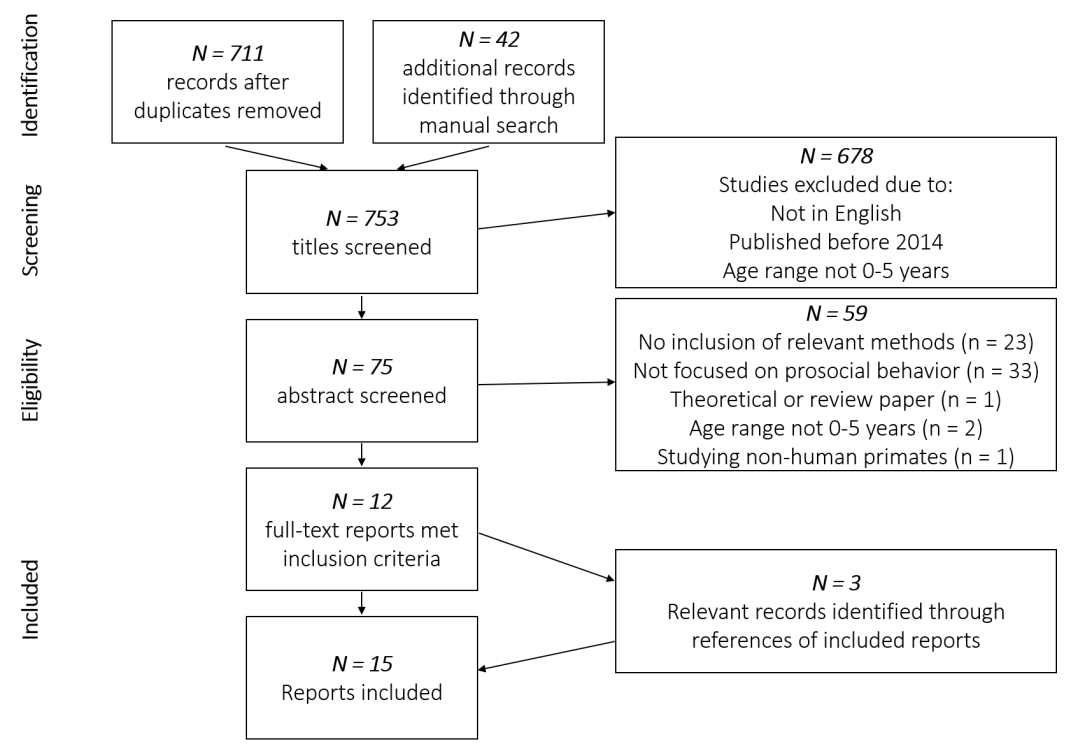

Figure 2. PRISMA flowchart illustrating search results and inclusion rates of Method search.

LMIC search. A total of $N=550$ records was identified once duplicates were discarded. Of these, $N=$ 508 were discarded as clearly irrelevant, and $N=42$ abstracts were screened. For this search, $N=11$ records were found to be eligible, the references of which were screened to identify additional relevant records. In total, $N=20$ reports were included for this search. The search process is illustrated in Figure 3. 


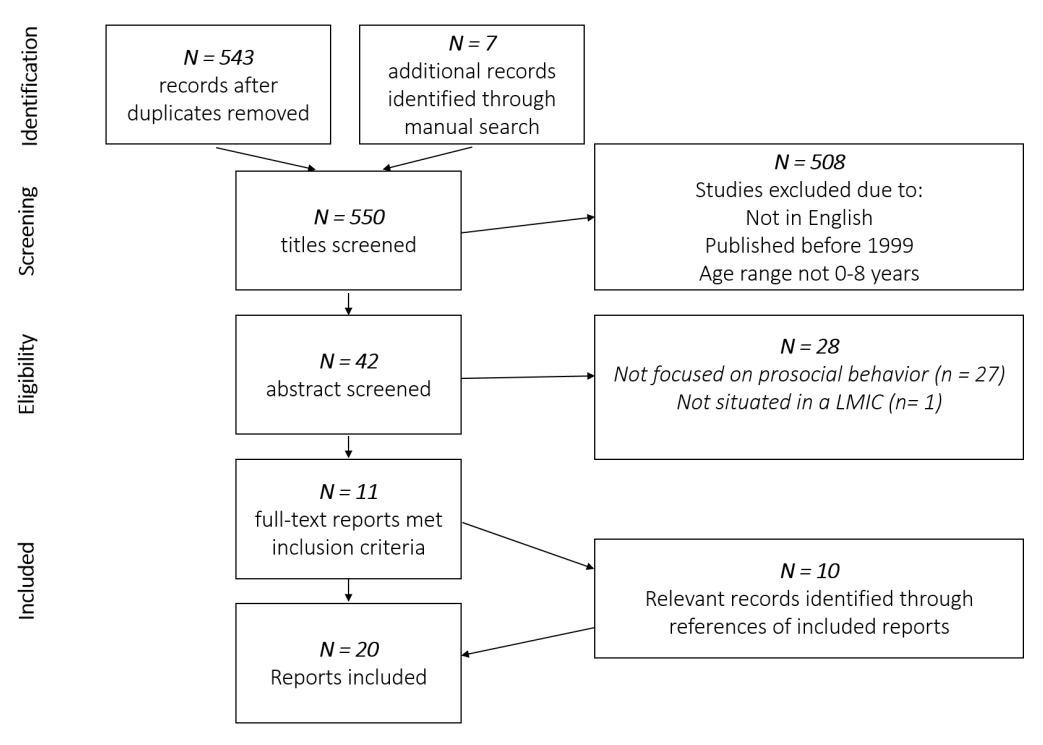

Figure 3. PRISMA flowchart illustrating search results and inclusion rates of LMIC search.

Study characteristics. Results from both searches can be found in Table 2. In terms of neurocognitive methods used, from the $N=15$ reports included for the Method search, $N=6$ used EEG/ERP measures, $N=6$ used eye tracking, and $N=3$ used a multimodal approach, which included one combined fNIRS and eye tracking study (Grossmann et al., 2018). The majority of studies $(N=7)$ examined helping, either via measuring participants overt helping behaviour and its associations with neurocognitive responses or by measuring EEG/eye tracking responses to helping vs harming scenarios. Participants' ages ranged from 6 months to 9 years (note that primarily findings up to 5 years will be discussed), with the majority of studies examining ages three-five years. Studies were overwhelmingly conducted in the US, the UK or other European countries.

As can be seen in Table 2, the 20 studies included in the LMIC search primarily assessed sharing behaviours $(N=9)$, often via behavioural resource allocation games. Other studies examined helping $(N=4)$, empathy $(N=2)$ or took a mixed domain approach $(N=4)$. Geographically, studies spanned the Americas, Africa, Europe, Asia and Oceania. Many studies $(N=12)$ included multiple sites and some also included high-income countries as an additional comparison group. Several studies examined differences between factors such as urbanisation or a study site, either within a country or across countries. Age ranges were higher than in studies from the Methods search, with the youngest participants tested at 18 months; oftentimes age ranges were also larger, spanning both early and middle childhood. Primarily, behavioural tasks and questionnaires were used, only two studies used eye tracking. 


\begin{tabular}{|c|c|c|c|c|c|c|}
\hline Citation & $\begin{array}{l}\text { Domain(s) of prosocial } \\
\text { development assessed }\end{array}$ & $\begin{array}{l}\text { Country/ies of } \\
\text { study }\end{array}$ & $\begin{array}{l}\text { Method used } \\
\text { (i.e. questionnaire/ behavioural } \\
\text { observation/ neuroimaging) }\end{array}$ & Age & $N$ & Main finding \\
\hline \multicolumn{7}{|c|}{ Studies using EEG, fNIRS or eye tracking } \\
\hline Cheng et al., 2014 & empathy & Taiwan & ERP, EEG & $\begin{array}{l}3-9 \text { years } \\
\text { and adults }\end{array}$ & $\begin{array}{l}57 \text { [stratified } \\
\text { across ages] }\end{array}$ & $\begin{array}{l}\text { ERP markers (N200 and LPP) elicited by painful and non-painful scenarios: N200 } \\
\text { (reflective of affective empathy) decreased with age, LPP (reflective of cognitive } \\
\text { empathy) increased. }\end{array}$ \\
\hline $\begin{array}{l}\text { Cowell \& Decety, } \\
\quad 2015 a\end{array}$ & sharing, helping & US & EEG, ERP, eye tracking & $3-5$ years & 57 & $\begin{array}{c}\text { Infants watched helping/hindering scenarios. Differences in late cognitive, but } \\
\text { not early sensory ERP component predicted sharing in a dictator game. Eye } \\
\text { tracking used to ensure infants' attention to scenes. }\end{array}$ \\
\hline $\begin{array}{l}\text { Cowell \& Decety, } \\
\text { 2015b }\end{array}$ & sharing, helping & US & EEG, ERP, eye tracking & $\begin{array}{l}12-24 \\
\text { months }\end{array}$ & 73 & $\begin{array}{c}\text { ERP and EEG power differences to helping/hindering scenarios. ERP differences } \\
\text { were associated with infants' preference for a prosocial character and with } \\
\text { parental attitudes towards fairness. Infants differentially attended helping vs } \\
\text { hindering characters, difference was not associated with sharing, or reaching } \\
\text { for the helper/hinderer puppet. }\end{array}$ \\
\hline $\begin{array}{l}\text { Cowell, Somerville \& } \\
\text { Decety, } 2019\end{array}$ & sharing & US & ERP & $4-8$ years & 83 & $\begin{array}{l}\text { ERP MFN component more negative when to unequal compared to equal } \\
\text { sharing scenarios. LPP was larger for extreme inequality in sharing. Individual } \\
\text { differences in LPP amplitude associated with children's sharing. }\end{array}$ \\
\hline $\begin{array}{l}\text { Crespo-Llado et al., } \\
2018\end{array}$ & $\begin{array}{l}\text { approach/withdrawal, } \\
\text { comforting }\end{array}$ & UK & EEG & 8 months & 32 & $\begin{array}{l}\text { Frontal alpha asymmetry was found in response to infants' observing a crying } \\
\text { but not a laughing peer. Approach to the peer in distress was more frequent in } \\
\text { infants showing greater left than right hemisphere activity. Infants with higher } \\
\text { left alpha activity were more likely to approach the peer. }\end{array}$ \\
\hline $\begin{array}{l}\text { Decety, } \\
\text { Meidenbauer \& } \\
\text { Cowell, } 2017\end{array}$ & empathy & US & EEG/ERP & $3.5-5$ years & 30 & $\begin{array}{l}\text { EEG/ERP measures differed between painful/non-painful stimuli and were } \\
\text { related to parental measures of empathy. }\end{array}$ \\
\hline $\begin{array}{l}\text { Gredebäck et al., } \\
2015\end{array}$ & helping & Sweden & ERP & 6 months & 14 & Differences in P400 components to helping or hindering agents. \\
\hline $\begin{array}{l}\text { Grossmann et al., } \\
2018\end{array}$ & helping, altruism & Germany & eye-tracking, fNIRS & $\begin{array}{l}7 \text { months } \\
\text { and } 14 \\
\text { months }\end{array}$ & 64 & $\begin{array}{c}\text { Attentional bias to fearful faces was associated with activation in dIPFC. } \\
\text { Attentional responses to fear in others at } 7 \text { months predicted altruistic } \\
\text { behaviour at } 14 \text { months. }\end{array}$ \\
\hline Hepach et al., 2017 & helping & Germany & eye tracking, pupillometry & $2-3$ years & 128 & $\begin{array}{l}\text { Increased pupil dilation in children when viewing someone they had harmed } \\
\text { but could not repair the harm. Not the case when viewing someone who a third } \\
\text { person had harmed or in cases where children were able to repair the harm. }\end{array}$ \\
\hline Hepach et al., 2019 & helping & Germany & eye tracking, pupillometry & $\begin{array}{c}1.5-5.5 \\
\text { years }\end{array}$ & $\begin{array}{l}109 \text { [stratified } \\
\text { across ages] }\end{array}$ & $\begin{array}{l}\text { Children's change in pupil dilation to a helping scenario associated with } \\
\text { likelihood and the latency until providing help. }\end{array}$ \\
\hline
\end{tabular}




\begin{tabular}{|c|c|c|c|c|c|c|}
\hline Holvoet et al., 2018 & $\begin{array}{l}\text { evaluation of sharing / } \\
\text { not sharing }\end{array}$ & France & eye tracking & 6 months & 31 & $\begin{array}{l}\text { Longer looking at other race agent and at prosocial agent. When the same-race } \\
\text { agent behaved prosocially, equal looking at same and other race agent. }\end{array}$ \\
\hline Köster at al., 2019 & $\begin{array}{l}\text { understanding others' } \\
\text { needs, helping }\end{array}$ & Germany & eye tracking & $\begin{array}{l}10 \text { and } 16 \\
\text { months }\end{array}$ & $\begin{array}{l}41[10 \text { months] } \\
37[16 \text { months }]\end{array}$ & $\begin{array}{c}\text { Infants' increasingly looked at individuals in need at } 10 \text { months, indicating } \\
\text { understanding of others' needs. Fine motor and social-communication skills } \\
\text { moderated the association of looking time at } 10 \text { months and behavioural } \\
\text { helping at } 16 \text { months. }\end{array}$ \\
\hline Köster et al., 2016 & $\begin{array}{l}\text { understanding others' } \\
\text { needs, helping }\end{array}$ & Germany & eye tracking & $\begin{array}{c}9-18 \\
\text { months }\end{array}$ & 71 & $\begin{array}{l}\text { Infants' anticipatory looking to helpers was found across all age groups, and } \\
\text { was not be correlated with infants' own helping behaviour. }\end{array}$ \\
\hline $\begin{array}{l}\text { Meidenbauer et al., } \\
2018\end{array}$ & $\begin{array}{l}\text { prosocial behaviour } \\
\text { and ingroup-bias }\end{array}$ & US & ERP & 4-7 years & 67 & $\begin{array}{l}\text { Children observed antisocial ingroup members and prosocial outgroup } \\
\text { members. Resulting changes in ingroup bias were predicted by changes in ERP } \\
\text { LPP component. }\end{array}$ \\
\hline \multicolumn{7}{|c|}{ Studies conducted in low- and middle-income countries } \\
\hline $\begin{array}{l}\text { Baker-Henningham } \\
\text { et al. (2019) }\end{array}$ & $\begin{array}{l}\text { helping, sharing, } \\
\text { comforting }\end{array}$ & Jamaica & $\begin{array}{l}\text { class-wide child prosocial } \\
\text { behaviour questionnaire, } \\
\text { Strengths and Difficulties } \\
\text { Questionnaire [teacher report] }\end{array}$ & $6-12$ years & $\begin{array}{l}108 \text { [intervention] } \\
112 \text { [control] }\end{array}$ & $\begin{array}{l}\text { The violence-based intervention programme showed effects on students' } \\
\text { academic attainment, but not their prosocial behaviour. }\end{array}$ \\
\hline Blake et al., 2015 & sharing & $\begin{array}{l}\text { Canada, India, } \\
\text { Mexico, Peru, } \\
\text { Senegal, } \\
\text { Uganda, USA }\end{array}$ & $\begin{array}{l}\text { behavioural sharing paradigm, } \\
\text { random resource allocation }\end{array}$ & $4-15$ years & $\begin{array}{l}866 \text { pairs of } \\
\text { children [stratified } \\
\text { across sites] }\end{array}$ & $\begin{array}{c}\text { Aversion towards disadvantageous inequity in all settings, at different age } \\
\text { points. Aversion towards advantageous inequity emerged in only US, Canada } \\
\text { and Uganda. Both types of inequity aversion affected by cultural factors, but } \\
\text { advantageous inequity aversion more so. }\end{array}$ \\
\hline Blake et al., 2016 & sharing & US, India & $\begin{array}{l}\text { behavioural, parents asked to } \\
\text { model fair or unfair sharing in a } \\
\text { dictator game, before their } \\
\text { children completed the task }\end{array}$ & $3-8$ years & $\begin{array}{c}163[\text { [US] } \\
154[\text { India] }\end{array}$ & $\begin{array}{l}\text { In India, parental models of both stingy and generous behaviour were copied. } \\
\text { In US, only the stingy behaviour. In India, the 3-4 year olds were not imitated, } \\
\text { but all were from } 5 \text { upwards. In the US the stingy influence present from 3-4 } \\
\text { years. }\end{array}$ \\
\hline Chen et al., 2013 & sharing & $\begin{array}{l}\text { China, eight } \\
\text { rural areas }\end{array}$ & $\begin{array}{l}\text { behavioural dictator game, } \\
\text { sharing with a stranger or a } \\
\text { friend }\end{array}$ & $\begin{array}{l}3.5-4.5 \\
\text { years }\end{array}$ & $\begin{array}{l}469 \text { [stratified } \\
\text { across sites] }\end{array}$ & $\begin{array}{l}\text { Children donated more stickers to friends compared to strangers, lower SES } \\
\text { children donated more than higher SES. Some children were left by their } \\
\text { parents who worked in an urban setting- this did not affect sharing behaviour } \\
\text { on this task. }\end{array}$ \\
\hline Chernyak et al., 2018 & $\begin{array}{l}\text { helping, sharing, } \\
\text { comforting }\end{array}$ & Zambia & $\begin{array}{l}\text { Behavioural, instrumental } \\
\text { helping, comforting } \\
\text { experimenter In distress, high } \\
\text { and low cost sharing }\end{array}$ & 3 years & 377 & $\begin{array}{c}\text { Costlier prosocial actions performed less: instrumental helping most common, } \\
\text { followed by comforting, lower cost giving, and higher cost giving. All prosocial } \\
\text { behaviours correlated with cognitive ability. Not objective, but subjective family } \\
\text { wealth predicted child's prosocial behaviours. }\end{array}$ \\
\hline Corbit et al., 2017 & $\begin{array}{l}\text { sharing, inequity } \\
\text { aversion }\end{array}$ & $\begin{array}{l}\text { India and } \\
\text { Canada }\end{array}$ & $\begin{array}{l}\text { behavioural sharing - inequity } \\
\text { aversion, children performed } \\
\text { alone or collaboratively with } \\
\text { another child }\end{array}$ & $\begin{array}{c}\text { 7-13 (rural } \\
\text { India) 4-10 } \\
\text { (rural } \\
\text { Canada) }\end{array}$ & $\begin{array}{c}116 \text { [India] } \\
132 \text { [Canada] }\end{array}$ & $\begin{array}{c}\text { Children either working in parallel, or cooperating with another child. } \\
\text { Advantageous inequity was sacrificed when children worked together, in order } \\
\text { to achieve equity between both partners. }\end{array}$ \\
\hline Cowell et al., 2017 & sharing & $\begin{array}{l}\text { Canada, China, } \\
\text { Turkey, South } \\
\text { Africa, USA }\end{array}$ & $\begin{array}{l}\text { behavioural dictator game, } \\
\text { child and a stranger }\end{array}$ & $5-12$ years & $\begin{array}{l}999 \text { [stratified } \\
\text { across sites] }\end{array}$ & $\begin{array}{l}\text { Generosity on a sharing task was predicted by children's executive functions } \\
\text { and second (but not first) order theory of mind. SES, culture, age, and gender } \\
\text { explained over } 20 \% \text { of variance in resource allocation. }\end{array}$ \\
\hline $\begin{array}{l}\text { Giner Torréns \& } \\
\text { Kärtner, } 2017\end{array}$ & helping & India, Germany & $\begin{array}{l}\text { behavioural live instrumental } \\
\text { helping paradigm, }\end{array}$ & 18 months & $\begin{array}{c}60 \text { [Germany] } \\
32 \text { [India] }\end{array}$ & $\begin{array}{l}\text { More helping in Indian than in German toddlers. Socialization practices } \\
\text { differed, Indian mothers reported more opportunities to help compared with } \\
\text { German mothers, and to praise less. Indian mothers used more punitive }\end{array}$ \\
\hline
\end{tabular}




\begin{tabular}{|c|c|c|c|c|c|c|}
\hline & & & $\begin{array}{l}\text { questionnaires on parents' } \\
\text { socialisation goals and practices }\end{array}$ & & & $\begin{array}{l}\text { practices than German mothers. Helping was positively associated with punitive } \\
\text { practices in the Indian sample, but negatively in German sample. }\end{array}$ \\
\hline $\begin{array}{l}\text { Hepach \& Herrmann, } \\
2019\end{array}$ & helping & $\begin{array}{l}\text { Kenya, } \\
\text { Germany }\end{array}$ & $\begin{array}{l}\text { screen-based instrumental } \\
\text { helping paradigm, } \\
\text { eye tracking }\end{array}$ & $3-9$ years & $\begin{array}{l}128 \text { Kenya, } \\
83 \text { Germany, split } \\
\text { across } 7 \text { age } \\
\text { groups, between } \\
\text { subject design }\end{array}$ & $\begin{array}{l}\text { German children looked longer at videos than Kenyan children, who looked } \\
\text { longer at the non-social compared to the social videos. Children of all ages in } \\
\text { both groups anticipated the solution to the helping scenario in the social but } \\
\text { not the non-social condition. No systematic changes in children's pupil dilation. }\end{array}$ \\
\hline House et al., 2013 & $\begin{array}{l}\text { cooperation, Sharing } \\
\text { (costly and non-costly) }\end{array}$ & $\begin{array}{c}\text { Australia, } \\
\text { Ecuador, } \\
\text { Namibia, } \\
\text { Central African } \\
\text { Republic, Fiji, } \\
\text { US }\end{array}$ & $\begin{array}{l}\text { behavioural resource allocation } \\
\text { paradigm, participants and } \\
\text { actor }\end{array}$ & $\begin{array}{l}\text { 3-14 years } \\
\text { adults }\end{array}$ & $\begin{array}{l}326 \text { [children, } \\
\text { stratified across } \\
\text { ages] } \\
120 \text { [adults] }\end{array}$ & $\begin{array}{c}\text { Costly sharing was low across all sites, non-costly sharing increased gradually } \\
\text { over childhood, older children's behaviour started to converge toward } \\
\text { observed adult levels within their communities. }\end{array}$ \\
\hline $\begin{array}{l}\text { Huang, Du \& Yin, } \\
2013\end{array}$ & empathy & China & stimulated distress procedures & $\begin{array}{l}10-26 \\
\text { months }\end{array}$ & 84 & $\begin{array}{c}\text { Proposed three-factor model (sympathy, personal distress and orientation) of } \\
\text { empathy in Chinese toddlers. }\end{array}$ \\
\hline Köster et al., 2016 & helping & $\begin{array}{l}\text { Germany, rural } \\
\text { and urban } \\
\text { Brazil }\end{array}$ & $\begin{array}{l}\text { instrumental helping, } \\
\text { questionnaires of parental } \\
\text { socialisation goals }\end{array}$ & $\begin{array}{l}18-30 \\
\text { months }\end{array}$ & $\begin{array}{c}38 \text { [Germany] } \\
34 \text { [rural Brazil] } \\
35 \text { [urban Brazil] }\end{array}$ & $\begin{array}{c}\text { Different maternal behaviours between countries, more assertive support by } \\
\text { Brazilian and more deliberate support by German mothers. The most prevalent } \\
\text { type of support was found to predict children's prosocial development in both } \\
\text { settings. }\end{array}$ \\
\hline Lohndorf et al., 2019 & guilt/remorse, empathy & Chile & $\begin{array}{l}\text { subsections of Child Conscience } \\
\text { Measure (CCM) questionnaire }\end{array}$ & $4-6$ years? & $\begin{array}{l}31 \text { [Chilean } \\
\text { majority] } \\
46 \text { [Mapouche } \\
\text { minority] }\end{array}$ & $\begin{array}{l}\text { Prosocial behaviour was not associated with children's SES. Parent report } \\
\text { measures found to not be ideal for this cultural context. }\end{array}$ \\
\hline Murray et al., 2016 & $\begin{array}{l}\text { instrumental helping } \\
\text { task }\end{array}$ & South Africa & $\begin{array}{l}\text { book reading intervention, } \\
\text { instrumental helping task }\end{array}$ & $\begin{array}{l}14-16 \\
\text { months }\end{array}$ & $\begin{array}{c}45 \text { [intervention] } \\
37 \text { [waitlist control] }\end{array}$ & $\begin{array}{l}\text { An eight-week book sharing intervention led to higher prosocial behaviour in } \\
\text { intervention compared to toy-play control group. }\end{array}$ \\
\hline $\begin{array}{l}\text { Parchment et al., } \\
2016\end{array}$ & $\begin{array}{l}\text { everyday prosocial } \\
\text { behaviour }\end{array}$ & South Africa & $\begin{array}{l}\text { Child Risk Behaviour Profile } \\
\text { questionnaire [parent report] }\end{array}$ & $9-13$ years & $\begin{array}{l}478 \text { [stratified } \\
\text { across ages] }\end{array}$ & $\begin{array}{l}\text { Caregivers' experience of social cohesion in community associated with better } \\
\text { social-emotional well-being, and positively related to their reports of children's } \\
\text { prosocial behaviour. }\end{array}$ \\
\hline Rajhans et al., 2016 & sharing, cooperating & India, Germany & eye tracking, dictator game & $4-5$ years & $\begin{array}{l}96 \text { [split across } \\
\text { sites] }\end{array}$ & $\begin{array}{l}\text { Increased altruistic behaviour was associated with a greater responsiveness to } \\
\text { fear faces (faster fixation), but not happy faces, in both cultures. }\end{array}$ \\
\hline Rao \& Stewart, 1999 & $\begin{array}{l}\text { sharing [spontaneous, } \\
\text { elicited, passive] }\end{array}$ & China, India & $\begin{array}{l}\text { observation of children's } \\
\text { sharing of preferred and non- } \\
\text { preferred foods }\end{array}$ & 4.5 years & $\begin{array}{l}36 \text { [China] } \\
36 \text { [India] }\end{array}$ & $\begin{array}{l}\text { Children were more likely to share spontaneously than to elicit sharing. Chinese } \\
\text { children shared more spontaneously than Indian children, who in turn shared } \\
\text { food passively. }\end{array}$ \\
\hline Rochat et al., 2009 & sharing, fairness & $\begin{array}{l}\text { China, USA, } \\
\text { Peru, Fiji, Brazil }\end{array}$ & sharing of food rewards & 3-5 years & $\begin{array}{c}41 \text { China } \\
26 \text { USA } \\
21 \text { Peru } \\
15 \text { Fiji } \\
27 \text { Brazil [city] } \\
29 \text { Brazil [slum] } \\
24 \text { Brazil [urban] }\end{array}$ & $\begin{array}{l}\text { In all settings, children showed little self-sacrifice or generosity. From age three, } \\
\text { link between perspective taking and prosociality. By } 5 \text { years, fairness in sharing } \\
\text { increases, across all sites. Differences in children's self-interest, with lower self- } \\
\text { interest in small-scale urban settings which promote collectivist values. }\end{array}$ \\
\hline Safra et al., 2016 & sharing, cooperating & Romania & quality dictator game & $6-7$ years & 39 & $\begin{array}{l}\text { Harshness of neighbourhood affects prosocial behaviour: children from harsher } \\
\text { neighbourhood behave less prosocially than their peers form a less harsh } \\
\text { environment. }\end{array}$ \\
\hline
\end{tabular}




\begin{tabular}{|c|c|c|c|c|c|c|}
\hline $\begin{array}{l}\text { Stewart \& McBride- } \\
\text { Chang, } 2000\end{array}$ & $\begin{array}{l}\text { sharing, moral } \\
\text { reasoning, empathy }\end{array}$ & $\begin{array}{l}\text { China, } \\
\text { Thailand, India, } \\
\text { Japan, } \\
\text { Australia, } \\
\text { South Africa, } \\
\text { Canada }\end{array}$ & $\begin{array}{l}\text { sharing of stickers/marbles, } \\
\text { either identified or anonymous, } \\
\text { questionnaire measure of } \\
\text { moral reasoning, parental } \\
\text { warmth and empathy }\end{array}$ & $\begin{array}{l}\text { No precise } \\
\text { age range } \\
\text { reported, } \\
\text { second } \\
\text { grade } \\
\text { children }\end{array}$ & $\begin{array}{l}98 \text { [stratified } \\
\text { across sites] }\end{array}$ & $\begin{array}{c}\text { Across Asian sites, girls were more likely to share when donations were } \\
\text { identifiable (rather than anonymous), across western sites no sex or sharing } \\
\text { condition difference was observed. At all sites, moral reasoning was associated } \\
\text { with sharing behaviour. Parental practices and moral reasoning were associated } \\
\text { with higher anonymous donations. }\end{array}$ \\
\hline
\end{tabular}

Note. $\mathrm{ERP}=$ event related potential, $\mathrm{EEG}=$ electroencephalography, $\mathrm{LPP}=$ late positive potential, MFN = medial frontal negativity, dIPFC $=$ dorsolateral prefrontal cortex, $\mathrm{SES}=$ socioeconomic status. 


\section{Discussion}

\section{Electrophysiological correlates of prosociality}

ERP markers. In the reviewed literature, the most commonly reported ERP component was the late positive potential (LPP), which depending on participants' age was occurred around 400ms at medial centro-parietal electrodes $(\mathrm{Cz}, \mathrm{Pz})$. The LPP is thought to reflect cognitive appraisal in processing prosocial actions (Cheng, Chen \& Decety, 2014), and has been shown to be associated with parental sensitivity to injustice (Cowell \& Decety, 2015b) and to correlate with prosocial behaviours (Decety, Meidenbauer \& Cowell, 2017; Meidenbauer et al., 2018; Cowell, Sommerville \& Decety, 2019), as well as preferences for prosocial vs antisocial agents (Cowell \& Decety, 2015a). Developmentally, increases in LPP amplitudes to socially relevant information are likely to reflect age-related gains in cognitive empathy (Cheng et al., 2014). The LPP has been reported in context of different facets of prosocial behaviour. Cheng and colleagues (2014) reported that viewing stimuli of someone in pain elicited larger LPPs compared to neutral stimuli in four to five year old children. Showing three to five year old children stimuli of another person in painful or neutral scenarios, Decety, Meidenbauer and Cowell (2017) reported that the difference in LPP amplitude between the two conditions was associated with variation in children's sharing behaviour. Similarly, three-five year old children's LPPs to helping vs harming scenarios appear to predict their subsequent sharing behaviour (Cowell \& Decety, 2015a). LPP differences have also been implicated in fairness perceptions in resource distribution. Cowell, Somerville and Decety (2019) found LPP differences between equal and slightly unequal, compared to extremely unequal sharing scenarios in four to eight year old-children. Meidenbauer and colleagues (2018) reported that an increased LPP for helping over harming behaviour, which was further affected by the actor's ingroup or outgroup membership. Children were assigned to one of two groups, and subsequently viewed scenarios including a prososically behaving outgroup- and an antisocially behaving ingroup members. The degree to which children showed a reduction in their in-group bias was associated with changes in the LPP to helping vs hindering scenarios. A functionally similar component has been identified in six month old infants. Gredebäck and colleagues (2015) describe a positive ERP component occurring at around 400ms (P400), which differed between helping vs hindering scenarios, but not in between to conditions in a visually matched control task. While labelled differently in this study, it is reasonable to assume that both the LPP and the P400 describe the same electrophysiological correlate, which can be observed throughout infancy and childhood and may thus prove a useful index of longitudinal changes in prosociality.

In line with its interpretation as a cognitively-driven correlate of a prosocial appraisal process, the LPP behaves differently from other commonly reported components. A range of early component have 
been reported in children observing prosocial vs anti-social or neutral stimuli. Decety, Meidenbauer and Cowell (2018) and Cheng and colleagues (2014) reported the occurrence of an early automatic component (termed EAC, N2 or N200) occurring at superior central locations (Cz) between 200$400 \mathrm{~ms}$ in response to watching depictions of pain vs neutral stimuli. Cowell, Sommerville and Decety (2019) reported a medial frontal negativity (MFN) measured between 275-400ms at fronto-central and lateral electrodes (F3/z/4) in response to equally vs unequal sharing scenarios. Lastly, Cowell \& Decety (2015a) reported an early posterior negativity (EPN), observed at 100-200ms over posterior (P3/z/4) electrodes in response to helping vs harming behaviours. Whereas the LPP can be understood as indicating a measure of cognitive appraisal of the presented stimuli, the earlier occurring components, have been attributed a merely discriminatory role between emotional valence of the presented stimuli (Cheng et al., 2014).

EEG power. In addition to ERP responses, changes in EEG power density and lateralisation have been studied as indicators of early prosocial development. Several studies have examined hemispheric asymmetries in alpha power (Crespo-Llado et al., 2018; Decety, Meidenbauer \& Cowell, 2018; Cheng et al., 2014) and adjacent frequency bands (5-8Hz, Cowell \& Decety, 2015a). Cheng and colleagues (2014) showed that in two- to nine-year-old children, suppression in the alpha range occurred for stimuli depicting painful and non-painful scenarios, but that the magnitude of this suppression did not differ between the two conditions. The condition difference was observed in adults, indicating a developmental shift, whereby a differential effect can only be obtained in older subjects.

Cowell and Decety (2015a) examined power changes in the $5-8 \mathrm{~Hz}$ range in three-to-five-year-old children watching helping and hindering scenarios, but did not find an overall effect for condition in activation changes. In a similar experiment with 12-24 month old toddlers, Cowell and Decety (2015b), demonstrated a global difference in $5-8 \mathrm{~Hz}$ band power density, with greater suppression for helping compared to hindering scenarios. They further observed a lateralisation effect, whereby greater left than right activation in response to hindering compared to helping scenarios. These results suggest that indices of lateralisation of power might provide a better indicator of the power dynamics underlying infants' and children's prosocial processes. Several groups have investigated lateralisation changes in EEG power. Decety, Meidenbauer and Cowell (2017) reported greater alpha suppression over frontal left lateralised electrodes occurring in three-to-five-year-old children watching painful vs neutral stimuli. Greater fronto-left alpha suppression was associated with parents' dispositional empathy. To understand the emergence of early comforting behaviour towards a peer in need, Crespo-Llado, Vanderwert, Roberti and Geangu (2018) presented eight-month-old infants with videos of laughing and crying peers whilst recording their EEG, coding their approach/withdrawal behaviours to the same videos in a subsequent session. Increased asymmetry of infants' frontal alpha 
activity was observed in response to the crying but not a laughing peer. Whereas at group level infants exhibited higher alpha activity over the right compared to the left hemisphere, behavioural approaches to the peer in distress were more frequent in those infants showing the opposite pattern of greater left than right hemisphere activity. These findings are in line with previous longitudinal research by Paulus and colleagues (2013), who reported associations of infants' resting state alpha asymmetries at 14 months of age and prosocial behaviour at 18 and 24 months of age. Greater left frontal activation was associated with comforting behaviours at 24 months of age. These findings may indicate a developmental shift, whereby differences in neural response patterns when observing different emotional states are associated with higher frequency of prosocial behaviours.

\section{Eye tracking measures of prosocial development}

Looking time measures. A large body of research has investigated infants' visual preference for pro-vs antisocially behaving agents. In terms of total looking time, mixed results have been reported as to infants' and children's increased attention to prosocial vs antisocial agents. Six-month-old infants show a longer total look duration at prosocially, compared to antisocially behaving agents (Holvoet et al., 2018). This bias is, however, partially overridden by other characteristics, as shown by increased looking time to other- vs own-race agents, highlighting the importance of stimulus choice in crosscultural studies. Similarly, 12-24 month old infants appear to attend longer to a helper compared to a helpee, but show no corresponding difference in hindering scenarios (Cowell \& Decety, 2015b). No relationship was found between looking behaviour and reaching for either the helper or the hinderer, or infants' sharing behaviour. In two to four year old children, Hinten et al. (2018) did not report differences between total look duration at a helping vs a hindering agent. Children did however look longer at scenarios during which a protagonist approached a helper vs a hinderer, which was not observed in young adults. This was tentatively interpreted in a violation of expectation framework, whereby children may have expected the helping agent to reciprocate and approach the protagonist, whereas no such expectation was formed for the hindering agent (Hinten et al., 2018). In line with this violation of expectation account, Köster and colleagues (2019) found that 10 month old infants looked longer at an agent who was helped, but did not require any help, compared to an agent needing help. While this indicated that infants had formed an understanding of others' needs, motor and social skills were found to moderate the link between prosocial understanding and helping behaviour at 16 months of age. These findings illustrate two issues in the interpretation of total looking time measures. Specifically, increased looking time can be interpreted both in terms of a preference of a behaviour and, perhaps more neutrally, as a violation of an expectation about a certain agent or a behaviour. More detailed analyses are needed to distinguish between these two 
competing interpretations that, alongside total attention allocation to a specific target, provide temporally precise information on attentional processes as they unfold.

Temporal measures looking behaviour. Alongside the emergence of overt helping behaviour, infants' understand the needs of others. In their study of 9-18 month old infants, Köster et al. (2016) presented infants with an agent in need. Infants showed anticipatory looking to a second helping character. Interestingly, no age effect was observed, even though levels of helping behaviour were found to be higher in older infants. Further, looking behaviour was not correlated with helping behaviour. It is suggested that an early understanding of others' needs is necessary, but not sufficient for the display of overt helping. Early attentional biases may capture one isolated aspect of prosocial development, which in combination with situational factors (i.e. recipient characteristics, costliness of behaviour) give rise to prosociality. In contrast, Grossmann et al. (2018) presented infants with fearful, happy and neutral faces at seven months and measured helping at 14 months of age and found that helping at 14 months was positively correlated with both overall attention to fearful (but not happy or angry) and the duration of first look to the fearful faces. This study indicates that, compared with a prospective longitudinal study, cross-sectional investigations are less likely to reveal an association between attentional biases and behavioural outcomes. It also highlights the potential of utilising measures of infants' affective responses (i.e. to emotional stimuli), which are consistently linked to helping behaviour (Marsh et al., 2014).

Pupillometry and arousal. Changes in pupil dilation, measured via pupillomtrey, are a consequence of activation in the sympathetic nervous system (Loewenfeld, 1993), and thus provide and indicator of changes in participants' arousal state. Hepach and colleagues (2017) showed larger increases in pupil dilation when viewing someone they had accidentally harmed, but were unable to repair the harm. This was not seen in instances where a third party had caused the harm or the harm could be repaired. This underlines the importance of pupil measures as a measure of arousal, rather than a mere saliency measure. Similarly, Hepach and colleagues (2019) reported results for 18-month to five year old children who were shown video versions of an instrumental helping task they subsequently participated in. The increase in pupil dilation/arousal was associated with latency to offer help in a subsequent experimental helping task. Thus, children's physiological responses to someone in need can predict their subsequent helping behaviour.

\section{Interplay of attentional processes, cortical activation and prosocial behaviour}

To our knowledge, only one study in the past five years investigated changes of prosocial development using fNIRS. In their longitudinal study, Grossmann and colleagues (2018) examined neural responses (fNIRS) and attention allocation (eye tracking) to fearful, angry and happy faces at 
seven months, and prosocial behaviour (helping) at 14 months of age. Total looking time at fearful faces and latency to first look to fearful faces predicted helping behaviour at 14 months. Combining attentional and fNIRS measures, it was shown that there was an association between look duration at fearful faces, but not latency to first look, and activity over the left dorsolateral prefrontal cortex (dIPFC). Activity in the left dIPFC was not associated with helping at 14 months, unless analyses were controlled for maternal engagement with their infant. When taking maternal engagement into account, left dIPFC activation was negatively associated with helping at 14 months. Looking at the difference between activation to fearful compared to angry faces, an association was found between activation in the right dIPFC and helping at 14 months, as well as with duration of first look to fearful faces at seven months, suggesting that enhanced discrimination between angry and fearful was associated with shorter first look at fearful faces. Taken together, these results do not suggest a clear lateralisation of function, but involvement of both left and right dIPFC in emotion discrimination, which may be a precursor or prosocial behaviour.

\section{Prosocial development in low- and middle- income countries}

Associations with cognitive development. Links between early cognitive development and prosocial behaviour have been observed across several distinct cultures. In a study of three year old Zambian children, Cernyak et al. (2013) found that children's performance on the Bayley Scales of Infant Development (Bayley, 2009) was associated with helping, sharing and comforting. In the context of a South-African book-sharing intervention with 14-16 month old infants, Murray et al. (2016) observed positive benefits for both infants' cognitive and their prosocial development. Cowell et al. (2017) assessed 5-12 year old children across five countries (US, South Africa, Turkey, China and Canada) and found that children's executive functions and second (but not first) order theory of mind predicted their generosity on a sharing task. It may be that more advanced theory of mind abilities enable an understanding of potential evaluation through a social partner, which may in turn lead to more extrinsically motivated prosocial behaviour. In support of this view, Stewart and McBride-Chang (2000) report higher sharing in an identifiable compared to an anonymous sharing task in children from different cultural backgrounds.

Huang, Du and Yin (2017) also report links between executive functions and prosocial behaviour; specifically, among 12-18 month old infants, empathy was associated with inhibitory control. Infants' ability to distinguish between the self and the other was hereby negatively associated with their experienced distress. While observing a peer's distress elicited distress in the participating infants, this relationship was mediated by their sense of self. From this it was concluded that as the sense of self develops, affectively driven empathy may decline, while cognitively controlled empathy increases. 
Others studies on links between executive functions and prosocial behaviour have reported null findings. For example, Lohndorf et al. (2019) found no association between these constructs in a study of Chilean four to six year old children. However, as the authors acknowledge, this null result may reflect the study's reliance on parental ratings of prosocial behaviour, using a measure that was not specifically developed or adapted for their setting. Similar methodological issues arise in the interpretation of a null effect of an intervention study in Jamaican school-aged children. BakerHenningham et al. (2019) reported that a violence reduction intervention in six year old students improved cognitive outcomes, but not class-wide prosociality, as assessed via the Strengths and Difficulties Questionnaire (Goodman, 1997). However, it cannot be determined in how far the lack of adaptation of the SDQ to the Jamaican context contributed to this finding.

Inter-vs intra-cultural variance. Developmental differences in prosociality are well-documented across cultures. However, there is an ongoing debate as to the contribution of within-, compared to between- culture variance to early prosocial development. There is some suggestion that family socioeconomic status (SES) affects prosocial development, and that within-site differences in SES could have a greater impact than between-site factors (Figure 2, Henrich et al., 2010).

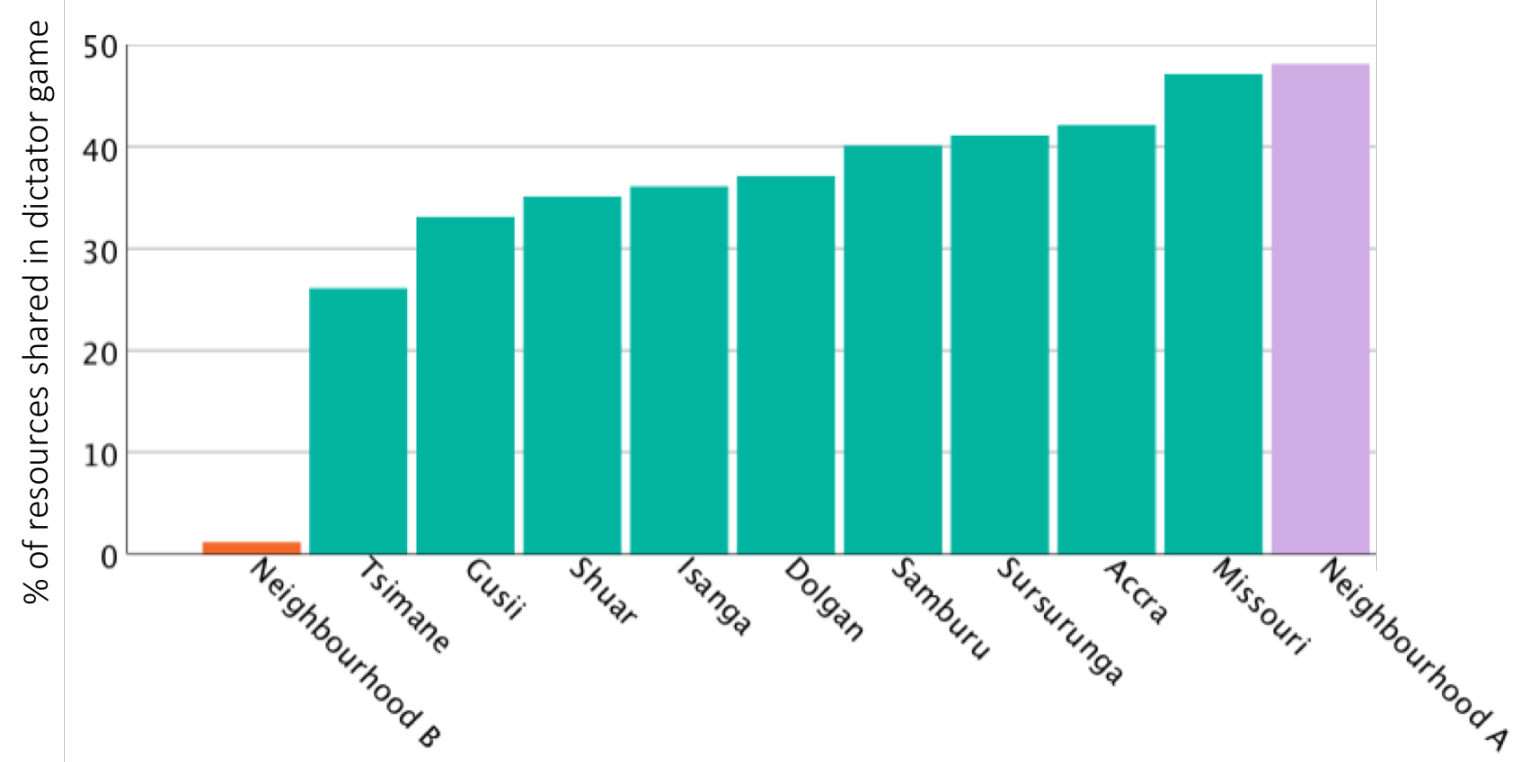

Population or Neighbourhood

Figure 4. Adapted from Safra et al., 2016. Mean dictator game offer in the deprived (B) and less deprived (A) neighbourhoods in Nettle et al. (2011) compared to mean population offers from cross-cultural data in Henrich et al. (2010). 
Comparing six- to seven-year-old Romanian children from high and low SES backgrounds, Safra et al. (2016) found that children at the lower end of the SES spectrum shared fewer toys compared to children from middle-SES families. In contrast, Chen et al. (2013) examined sharing behaviour in two to three year old children in eight areas in rural China and observed no differences between settings. These findings raise the question as to the mechanistic link between SES and prosocial development. Safra et al. (2016) propose a non-linear relationship, whereby low as well as high SES is associated with fewer prosocial behaviours, due to either the need to preserve resources or competitiveness in behaviour leading to less sharing. Another consideration is the influence of SES on parental behaviour toward the child, in turn affecting prosocial development. Chernyak and colleagues (2018) suggest that rather than objective metrics of SES, parental perceptions of their SES within the community could affect prosocial development. Hereby, SES was associated with mothers' behaviour towards their child, with higher subjective SES being associated with more encouragement of sharing and helping.

Cultural norms. In a study documenting the impact of growing up in a collectivist vs an individualist culture, Rao and Stewart (1999) found that four year old children from collectivist backgrounds (China and India) shared more than children from the US. While American children were more likely to elicit sharing from their partner, Chinese children were more likely to share spontaneously and Indian children shared passively, by allowing their partner access to their resources. Stewart and McBrideChang (2000) reported a trend towards higher sharing in children from collectivist cultures. They further reported sex differences for collectivist, but not individualist cultures, with girls in collectivist settings sharing more than boys. Parental practices emphasizing orientation to others were more prevalent in the collectivist contexts, and were found to predict sharing across all settings. Across all study sites, children's moral reasoning abilities were positively associated with sharing. Similar observations were made with regard to fairness. Rochat et al. (2009) found that fairness in sharing at three years of age is higher in children in countries with collectivist orientation, but that developmental gains from three to five years of age follow similar trajectories in both individualist and collectivist settings. While these findings indicate a benefit of other vs self-oriented values for prosocial development, substantial intra-cultural differences in the adoption of these values exist, making paradigms relying on binary categorisation on the country level problematic (Cowell et al., 2017). A closer examination of parenting factors holds potential to reduce inter-regional and interindividual variations.

Parental influences. In a study of 18 month old infants from India and Germany, Giner Torréns \& Kärtner (2017) observed Indian infants to help more frequently during an instrumental helping task than German infants. Some associations were found between parental reports of 1) offering helping 
opportunities in the home environment, 2) praising of infants' helping behaviour in the home and 3) punitive parenting strategies were related to infants' helping on the instrumental helping paradigm. Overall, Indian mothers reported more opportunities for infant helping, less praising and more punitive practices to non-compliance compared to the German mothers. Infant helping was positively associated to punitive practices in the Indian sample, but negatively associated with punitive practice and helping opportunities in the German sample. The authors conclude that cultural factors affect infants' prosocial behaviour from the onset, and further propose a mediating relationship of parenting strategies, whereby culture affects parent behaviour, which in turn affects infants' prosocial behaviour. Köster et al. (2016) provide some evidence that adopting the prevalent parenting style of a given context may result in more frequent prosocial behaviour. Studying 18-30 month old children in Brazil and Germany, they demonstrated that Brazilian mothers were more assertive, while German mothers were more deliberate in their scaffolding of prosocial behaviour. In both cases however, adherence to the respective dominant parenting style was associated with higher level of prosocial behaviour in their infants. Examining parental reports of their children's prosocial development, Parchment et al. (2016) found that higher ratings were associated with parental perceptions of the social cohesion within their communities. In addition to the observational studies reported above, Blake et al. (2016) experimentally measured the sharing behaviour of three to eight year old children in the US and India, after instructing their parents to model either generous or stingy sharing scenarios. The Indian children were shown to imitate parental sharing in both conditions, whereas in the US only the generous sharing model impacted children's sharing. Further, differential developmental trajectories were observed, whereby children in India imitated their parents more from around five years of age, whereas the US children showed imitation of only stingy behaviours from three years onwards. However, in a study of Chilean five year olds, Lohndorf et al. (2019) did not find associations between the quality of maternal care, the home environment and prosocial behaviour. As discussed above, methodological issues in measuring prosocial behaviour in this study however call into question the validity of this finding.

Universality vs cultural specificity. Some evidence suggests that affectively driven prosocial behaviours may be more universal than cognitively driven prosocial behaviours. Studying 4 to 15 year old participants across seven countries (Canada, India, Mexico, Peru, Senegal, Uganda, USA), Blake et al. (2015) demonstrated developmental differences for advantageous vs disadvantageous sharing. Participants were asked to accept or reject resource allocation that were either distributed fairly, favouring the participant (advantageous inequity) or favouring their sharing partner (disadvantageous inequity). Aversion to disadvantageous inequity was universal, but differed in timing of onset across countries, being evident as early as four to six years in the USA and Canada, but only by 10 years of 
age in Mexico. In contrast, participants from just three countries (USA, Canada and Uganda) showed aversion to advantageous inequity. The driving mechanisms for disadvantageous and advantageous inequity aversion are hypothesised to differ, with the former being a motivated by emotional reactions to unfairness, whereas the latter is reliant on moral reasoning.

A similar distinction has been proposed for costly vs costless prosocial behaviours, whereby costless behaviours have been shown to increase with age across diverse societies, while costly behaviours differed across settings (House et al., 2013). From middle childhood, costly behaviours started to converge toward a level typical for adults in the respective society. House et al. (2013) studied participants across six societies across the Americas (North American; Shuar, Ecuador), Africa (Himba, Namibia; Aka, Central African Republic), and Oceania (Martu, Australia; Fijian, Yasawa Island). The groups assessed varied widely in terms of their culture, geographical location and subsistence strategies. Cross sectional assessments on a dictator game were performed on participants starting at three years of age and assessing all ages up to age 14 years, as well as on a cohort of adults from each site. Prosocial (sharing) behaviour was observed across all societies in early childhood. Rates of sharing subsequently dropped throughout middle childhood in those scenarios where sharing came at a cost for the participant. Behaviour of older children and adolescents varied between cultures, with responses of adolescents starting to resemble those of adults from their communities. The authors conclude that prosocial behaviour is adopted relatively uniformly in early childhood, but that these early behaviours do not necessarily shape prosocial behaviour in a population-specific manner.

Contextual factors. A number of factors have been found to interact with cultural influences on prosocial development. The costliness of a given behaviour has been identified to play a role. Chernyak et al. (2013) describe overall lower levels of sharing, helping and comforting among their three-year-old Zambian participants. Examining inequity aversion, Corbit et al. (2017) presented 4-13 year old children in India and Canada with advantageous and disadvantageous inequity scenarios. Prior to this, children were asked to work on an unrelated task either in collaboration, or in parallel, making it possible to investigate how prior cooperation affects later sharing. Disadvantageous inequity aversion was prevalent in both conditions, whereas advantageous inequity aversion was seen more frequently in those pairs that had been cooperating.

Emerging neurocognitive investigations. To date, two studies have begun to investigate neurocognitive correlates of prosocial development in low and middle-income settings. In an eye tracking study of three-nine year old children from Nanyuki, Kenya and Leipzig, Germany, Hepach and Herrmann (2019) presented participants with a video stimulus of a person playing a stacking game. They then dropped one of the stacked items (relevant item) as well as another item (irrelevant item) 
to the floor and ambiguously reached for them. A second agent observing the scene subsequently returned the irrelevant object. In a non-social condition, all objects moved in the same way, but no actors were present. Children of both cultures and all ages anticipated the solution in the social condition (increased looking time to the relevant over the irrelevant object) but not the non-social condition. Children differed however on their baseline looking, with Kenyan children looking more at the non-social stimuli and German children looking longer overall. This was attributed to an overall decreased familiarity of the Kenyan infants with objects moving on their own account and highlights the importance of differences in cultural exposures when designing tasks. Pupil dilatation was examined and a weak effect was found for greater dilation in response to seeing the objects being dropped in the social compared to the non-social condition. This finding aligns with prior work by Hepach et al., (2019), where German two year olds were found to have increased pupil dilation in response to the social condition on the same task. The authors do however suggest that this effect may not generalise to older age groups studied here, as well to other cultures. Another eye tracking study examined infants' visual attention, which has been shown to be predictive of their later prosocial behaviour (i.e. Grossmann et al., 2018). Rajhans et al. (2016) studied links between face processing and prosocial behaviour in five-year-old children in India and Germany. Across both cultures, higher sensitivity to fearful facial expressions (as indicated by faster fixation) was associated with greater prosocial behaviour in the dictator game.

\section{Conclusion}

While eye tracking methods have started to inform the cross-cultural knowledge base in this field, there is, as highlighted by Lohndorf et al. (2019) and Baker-Henningham et al. (2019), an ongoing need to validate accompanying measures (i.e. parent report of prosocial behaviour) when implemented in novel settings. Further, while current eye tracking investigations primarily use measures of total looking time, additional markers could inform more subtle changes in early visual attention and its association with prosocial development. Many applications of eye tracking have not yet been realised in cross-cultural research, such as pupillometry-based measures of arousal changes (Grossmann et al., 2018; Hepach, Vaish, \& Tomasello, 2015), or the reliance on early biases associated with prosocial development like attention to fearful faces (Grossmann et al., 2018; Rajhans et al., 2016). Further, there is a need for thorough characterisation of samples selected for cross-cultural comparisons, reducing the reliance on individualist vs collectivist distinctions, and considering individual differences in relevant variables (parenting factors, SES, costliness of behaviour, recipient characteristics) alongside the developmental outcome.

In addition to considerations frequently arising in neurodevelopmental research (narrow age ranges, limited sample sizes), the current literature highlights several starting points for future investigations. 
First, in common with many other fields of developmental psychology, longitudinal investigations are relatively uncommon, despite their importance for addressing issues of developmental change and continuity, and uncover longer-term neurodevelopmental processes (i.e. Grossmann et al., 2019). Hereby, some indices, such as the ERP LPP response, have been shown to show age-related changes throughout infancy and early childhood, and may thus provide a valuable starting point in longitudinal investigations. Moreover, studies that involved several age groups often failed to report age related differences. In part, this may reflect the fact that some outcome measures (i.e. reaching for helper agent, looking longer at helping than hindering), once mastered, do not necessarily change with age. Investigations of age-related change might however be addressed by measuring latency-to-touch or reaction time to gaze shift towards a helping agent. Second, while there are some interesting findings on the early correlates of individual differences in prosocial behaviour, research in this field has yet to extend to younger age groups, for whom EEG, fNIRS and eye tracking offer great potential. By utilizing well-documented early social biases (orienting towards faces, voices and biological motion) in context of later prosocial tendencies, the work by Grossmann et al. (2018), hereby provides an interesting basis for future work. The vast ERP literature on the early trajectories of face processing could also find an application to investigate the early building blocks giving rise to prosocial behaviour. There also is a relative lack of EEG work on prosocial behaviour in infant cohorts. Some paradigms (i.e. Cowell \& Decety, 2015) have yielded very interesting results in young children, and, not being reliant on advanced motor responses, might offer a good starting point to extend this research downward into the infant period.

Alongside these general methodological challenges and solutions, researchers investigating early development and individual differences in prosocial behaviour face a more specific set of challenges that relate to the multi-faceted nature of prosocial behaviour. Numerous lines of evidence (including twin studies) show that these three types of prosocial behaviour are likely to have quite different origins. In particular, genetic factors account for a substantial proportion of variation in infants' empathic responses (about 50\%) and a modest proportion of variation in infants' sharing responses (about 25\%), but do not contribute to variation in infants' helping responses. These contrasting findings lead to the prediction that, infants' helping responses are likely to be culturally specific, but infants' responses to others' distress is likely to be relatively universal. Cross-cultural studies, which are likely to encompass a larger variety of family structures and caregiving practices than is common in WEIRD settings can play a vital role in disentangling genetic and social influences on prosocial development.

Neurocognitive methods are rarely included in cross-cultural investigations of prosocial development and yet hold great promise for future research. Our aim in this review has been to document the 
conceptual and methodological challenges and solutions within existing research on the neurocognitive underpinnings of early prosocial development across different cultural settings. We believe that this emerging field holds real potential for advancing our understanding of the processes that underpin early social influences on infant and child development. In particular, electrophysiological, fNIRS and eye-tracking measures each offer researchers a scope for gathering precise information about the rapid neural responses that underpin infants' sensitivity to social cues, identified by Darwin almost 150 years ago.

\section{Funding}

This work was supported through an ESRC Postdoctoral Fellowship held by the first author [grant number ES/T008644/1]. The work of the Evidence for Better Lives Study was supported by the Jacobs Foundation, UBS Optimus Foundation, Fondation Botnar, the Consuelo Zobel Alger Foundation, the British Academy, the Cambridge Humanities Research Grants Scheme, the ESRC Impact Acceleration Account Programme, the Queensland University Postgraduate Research Award. The views expressed are those of the authors and not necessarily those of the founders.

\section{Competing interests}

The authors declare no conflict of interest. 


\section{References}

Baker-Henningham, H., Scott, Y., Bowers, M., \& Francis, T. (2019). Evaluation of a violence-prevention programme with Jamaican primary school teachers: A cluster randomised trial. International journal of environmental research and public health, 16(15), 2797.

Bayley, N. (2009). Bayley-III: Bayley Scales of infant and toddler development. Giunti OS.

Beam, C. R., \& Turkheimer, E. (2013). Phenotype-environment correlations in longitudinal twin models. Development and psychopathology, 25(1), 7-16.

Benenson, J. F., Pascoe, J., \& Radmore, N. (2007). Children's altruistic behavior in the dictator game. Evolution and Human Behavior, 28(3), 168-175.

Blake, P. R., Corbit, J., Callaghan, T. C., \& Warneken, F. (2016). Give as I give: Adult influence on children's giving in two cultures. Journal of Experimental Child Psychology, 152, 149-160.

Blake, P. R., McAuliffe, K., Corbit, J., Callaghan, T. C., Barry, O., Bowie, A., ... \& Wrangham, R. (2015). The ontogeny of fairness in seven societies. Nature, 528(7581), 258

Blasi, A., Lloyd-Fox, S., Katus, L., \& Elwell, C. E. (2019, September). fNIRS for tracking brain development in the context of global health projects. In Photonics (Vol. 6, No. 3, p. 89). Multidisciplinary Digital Publishing Institute.

Bloom, P. (2017). Empathy and its discontents. Trends in cognitive sciences, 21(1), 24-31.

Borke, H. (1973). The development of empathy in Chinese and American children between three and six years of age: A cross-cultural study. Developmental psychology, 9(1), 102.

Brownell, C. A., Svetlova, M., Anderson, R., Nichols, S. R., \& Drummond, J. (2013). Socialization of early prosocial behavior: Parents' talk about emotions is associated with sharing and helping in toddlers. Infancy, 18(1), 91-119.

Brownell, C. A., Svetlova, M., Anderson, R., Nichols, S. R., \& Drummond, J. (2013). Socialization of early prosocial behavior: Parents' talk about emotions is associated with sharing and helping in toddlers. Infancy, 18(1), 91-119.

Callaghan, T., \& Corbit, J. (2018). Early prosocial development across cultures. Current opinion in psychology, 20, 102-106.

Callaghan, T., Moll, H., Rakoczy, H., Warneken, F., Liszkowski, U., Behne, T., ... \& Collins, W. A. (2011). Early social cognition in three cultural contexts. Monographs of the society for research in child development, i-142.

Chen, Y. C., Chen, C. C., Decety, J., \& Cheng, Y. (2014). Aging is associated with changes in the neural circuits underlying empathy. Neurobiology of aging, 35(4), 827-836.

Chen, Y., Zhu, L., \& Chen, Z. (2013). Family income affects children's altruistic behavior in the dictator game. PLoS One, 8(11), e80419.

Chernyak, N., Harvey, T., Tarullo, A. R., Rockers, P. C., \& Blake, P. R. (2018). Varieties of young children's prosocial behavior in Zambia: The role of cognitive ability, wealth, and inequality beliefs. Frontiers in psychology, 9, 2209

Corbit, J., McAuliffe, K., Callaghan, T. C., Blake, P. R., \& Warneken, F. (2017). Children's collaboration induces fairness rather than generosity. Cognition, 168, 344-356.

Cowell, J. M., \& Decety, J. (2015). Precursors to morality in development as a complex interplay between neural, socioenvironmental, and behavioral facets. Proceedings of the National Academy of Sciences, 112(41), 12657-12662.

Cowell, J. M., \& Decety, J. (2015). The neuroscience of implicit moral evaluation and its relation to generosity in early childhood. Current Biology, 25(1), 93-97.

Cowell, J. M., Calma-Birling, D., \& Decety, J. (2018). Domain-general neural computations underlying prosociality during infancy and early childhood. Current opinion in psychology, 20, 66-71.

Cowell, J. M., Lee, K., Malcolm-Smith, S., Selcuk, B., Zhou, X., \& Decety, J. (2017). The development of generosity and moral cognition across five cultures. Developmental science, 20(4), e12403.

Cowell, J. M., Lee, K., Malcolm-Smith, S., Selcuk, B., Zhou, X., \& Decety, J. (2017). The development of generosity and moral cognition across five cultures. Developmental science, 20(4), e12403.

Cowell, J. M., Sommerville, J. A., \& Decety, J. (2019). That's not fair: Children's neural computations of fairness and their impact on resource allocation behaviors and judgments. Developmental psychology.

Crespo-Llado, M. M., Vanderwert, R., Roberti, E., \& Geangu, E. (2018). Eight-month-old infants' behavioral responses to peers' emotions as related to the asymmetric frontal cortex activity. Scientific reports, 8(1), 17152.

Darwin, C. (1872). 1965. The expression of the emotions in man and animals. London, UK: John Marry. 
de Waal, F. B., \& Preston, S. D. (2017). Mammalian empathy: behavioural manifestations and neural basis. Nature Reviews Neuroscience, 18(8), 498.

Decety, J., Lewis, K. L., \& Cowell, J. M. (2015). Specific electrophysiological components disentangle affective sharing and empathic concern in psychopathy. Journal of Neurophysiology, 114(1), 493-504.

Decety, J., Meidenbauer, K. L., \& Cowell, J. M. (2018). The development of cognitive empathy and concern in preschool children: a behavioral neuroscience investigation. Developmental Science, 21(3), e12570.

Decety, J., Meidenbauer, K. L., \& Cowell, J. M. (2018). The development of cognitive empathy and concern in preschool children: a behavioral neuroscience investigation. Developmental Science, 21(3), e12570.

Dunfield, K. A. (2014). A construct divided: prosocial behavior as helping, sharing, and comforting subtypes. Frontiers in Psychology, 5, 958.

Dunfield, K., Kuhlmeier, V. A., O'Connell, L., \& Kelley, E. (2011). Examining the diversity of prosocial behavior: Helping, sharing, and comforting in infancy. Infancy, 16(3), 227-247.

Eisenberg, N., Fabes, R. A., \& Spinrad, T. L. (2007). Prosocial development. Handbook of child psychology, 3.

Fehr, E., Bernhard, H., \& Rockenbach, B. (2008). Egalitarianism in young children. Nature, 454(7208), 1079.

Giner Torréns, M., \& Kärtner, J. (2017). The influence of socialization on early helping from a cross-cultural perspective. Journal of Cross-Cultural Psychology, 48(3), 353-368.

Goodman, R. (1997). The Strengths and Difficulties Questionnaire: a research note. Journal of child psychology and psychiatry, 38(5), 581-586.

Gredebäck, G., Kaduk, K., Bakker, M., Gottwald, J., Ekberg, T., Elsner, C., ... \& Kenward, B. (2015). The neuropsychology of infants' pro-social preferences. Developmental Cognitive Neuroscience, 12, 106-113.

Grossmann, F. (2018). Theoretical femtosecond physics: atoms and molecules in strong laser fields. Springer.

Gummerum, M., Hanoch, Y., Keller, M., Parsons, K., \& Hummel, A. (2010). Preschoolers' allocations in the dictator game: The role of moral emotions. Journal of Economic Psychology, 31(1), 25-34.

Haidt, J., Koller, S. H., \& Dias, M. G. (1993). Affect, culture, and morality, or is it wrong to eat your dog?. Journal of personality and social psychology, 65(4), 613.

Hamlin, J. K. (2013). Moral judgment and action in preverbal infants and toddlers: Evidence for an innate moral core. Current Directions in Psychological Science, 22(3), 186-193.

Hamlin, J. K. (2014). Context-dependent social evaluation in 4.5-month-old human infants: The role of domain-general versus domain-specific processes in the development of social evaluation. Frontiers in Psychology, 5, 614.

Hamlin, J. K. (2015). The case for social evaluation in preverbal infants: gazing toward one's goal drives infants' preferences for Helpers over Hinderers in the hill paradigm. Frontiers in Psychology, 5, 1563.

Hamlin, J. K., \& Wynn, K. (2011). Young infants prefer prosocial to antisocial others. Cognitive development, 26(1), 30-39.

Hamlin, J. K., Wynn, K., \& Bloom, P. (2007). Social evaluation by preverbal infants. Nature, 450(7169), 557.

Hamlin, J. K., Wynn, K., \& Bloom, P. (2010). Three-month-olds show a negativity bias in their social evaluations. Developmental science, 13(6), 923-929.

Hamlin, J. K., Wynn, K., Bloom, P., \& Mahajan, N. (2011). How infants and toddlers react to antisocial others. Proceedings of the national academy of sciences, 108(50), 19931-19936.

Hammond, S. I., \& Brownell, C. A. (2018). Happily Unhelpful: Infants' Everyday Helping and its Connections to Early Prosocial Development. Frontiers in psychology, 9, 1770.

Henrich, J., Ensminger, J., McElreath, R., Barr, A., Barrett, C., Bolyanatz, A., ... \& Lesorogol, C. (2010). Markets, religion, community size, and the evolution of fairness and punishment. science, 327(5972), 1480-1484.

Henrich, J., Heine, S. J., \& Norenzayan, A. (2010). Most people are not WEIRD. Nature, 466(7302), 29.

Hepach, R., \& Herrmann, E. (2019). The development of prosocial attention across two cultures. Frontiers in psychology, 10.

Hepach, R., Vaish, A., \& Tomasello, M. (2017). Children's intrinsic motivation to provide help themselves after accidentally harming others. Child development, 88(4), 1251-1264.

Hepach, R., Vaish, A., Müller, K., \& Tomasello, M. (2019). The relation between young children's physiological arousal and their motivation to help others. Neuropsychologia, 126, 113-119.

Heyes, C. (2018). Empathy is not in our genes. Neuroscience \& Biobehavioral Reviews. 
Hinten, A. E., Labuschagne, L. G., Boden, H., \& Scarf, D. (2018). Preschool children and young adults' preferences and expectations for helpers and hinderers. Infant and Child Development, 27(4), e2093.

Hoff, G. E., Van Den Heuvel, M., Benders, M. J., Kersbergen, K. J., \& de Vries, L. S. (2013). On development of functional brain connectivity in the young brain. Frontiers in Human Neuroscience, 7, 650.

Holvoet, C., Arciszewski, T., Scola, C., \& Picard, D. (2018). Infants' Visual Preferences for Prosocial Behavior and Other-Race Characters at 6 Months: An Eye-Tracking Study. SAGE Open, 8(2), 2158244018784993.

House, B. R., Silk, J. B., Henrich, J., Barrett, H. C., Scelza, B. A., Boyette, A. H., ... \& Laurence, S. (2013). Ontogeny of prosocial behavior across diverse societies. Proceedings of the National Academy of Sciences, 110(36), 14586-14591.

Huang, H., Su, Y., \& Jin, J. (2017). Empathy-Related Responding in Chinese Toddlers: Factorial Structure and Cognitive Contributors. Infant and child development, 26(3), e1983.

Hur, Y., Taylor, J., Jeong, H., Park, M., \& Haberstick, B. (2017). Perceived Family Cohesion Moderates Environmental Influences on Prosocial Behavior in Nigerian Adolescent Twins. Twin Research and Human Genetics, 20(3), 226-235. doi:10.1017/thg.2017.15

Israel, S., Hasenfratz, L., \& Knafo-Noam, A. (2015). The genetics of morality and prosociality. Current Opinion in Psychology, 6, 55-59.

Johnson, M. H. (2014). Autism: demise of the innate social orienting hypothesis. Current Biology, 24(1), R30-R31.

Kärtner, J., Keller, H., \& Chaudhary, N. (2010). Cognitive and social influences on early prosocial behavior in two sociocultural contexts. Developmental psychology, 46(4), 905.

Kärtner, J., Schuhmacher, N., \& Collard, J. (2014). Socio-cognitive influences on the domain-specificity of prosocial behavior in the second year. Infant Behavior and Development, 37(4), 665-675.

Katus, L., Hayes, N., McCann, S., Mason, L., Blasi, A., Darboe, M. K., ... \& Elwell, C. E. (2019). Implementing neuroimaging and eye tracking methods to assess neurocognitive development of young infants in low-and middle-income countries. Gates Open Research, 3.

Kennedy, D. P., \& Adolphs, R. (2012). The social brain in psychiatric and neurological disorders. Trends in cognitive sciences, 16(11), 559-572.

Knafo-Noam, A., Vertsberger, D., \& Israel, S. (2018). Genetic and environmental contributions to children's prosocial behavior: brief review and new evidence from a reanalysis of experimental twin data. Current opinion in psychology, 20, 6065.

Knafo, A., \& Israel, S. (2009). Genetic and environmental influences on prosocial behavior. Prosocial motives, emotions, and behavior: The better angels of our nature, 149-167.

Knafo, A., Israel, S., \& Ebstein, R. P. (2011). Heritability of children's prosocial behavior and differential susceptibility to parenting by variation in the dopamine receptor D4 gene. Development and psychopathology, 23(1), 53-67.

Korndörfer, M., Egloff, B., \& Schmukle, S. C. (2015). A large scale test of the effect of social class on prosocial behavior. PloS one, 10(7), e0133193.

Köster, M., Cavalcante, L., Vera Cruz de Carvalho, R., Dôgo Resende, B., \& Kärtner, J. (2016). Cultural influences on toddlers' prosocial behavior: How maternal task assignment relates to helping others. Child development, 87(6), 1727-1738.

Köster, M., Cavalcante, L., Vera Cruz de Carvalho, R., Dôgo Resende, B., \& Kärtner, J. (2016). Cultural influences on toddlers' prosocial behavior: How maternal task assignment relates to helping others. Child development, 87(6), 1727-1738.

Köster, M., Itakura, S., Omori, M., \& Kärtner, J. (2019). From understanding others' needs to prosocial action: Motor and social abilities promote infants' helping. Developmental science, e12804.

Köster, M., Ohmer, X., Nguyen, T. D., \& Kärtner, J. (2016). Infants understand others' needs. Psychological science, 27(4), 542-548.

Köster, M., Schuhmacher, N., \& Kärtner, J. (2015). A cultural perspective on prosocial development. Human Ethology Bulletin, 30(1), 71-82.

Kuhlmeier, V., Wynn, K., \& Bloom, P. (2003). Attribution of dispositional states by 12-month-olds. Psychological science, 14(5), 402-408.

Lan, X., Legare, C. H., Ponitz, C. C., Li, S., \& Morrison, F. J. (2011). Investigating the links between the subcomponents of executive function and academic achievement: A cross-cultural analysis of Chinese and American preschoolers. Journal of experimental child psychology, 108(3), 677-692. 
Lindsley, D. B. (1939). A longitudinal study of the occipital alpha rhythm in normal children: Frequency and amplitude standards. The Pedagogical Seminary and Journal of Genetic Psychology, 55(1), 197-213.

Lloyd-Fox, S., Blasi, A., \& Elwell, C. E. (2010). Illuminating the developing brain: the past, present and future of functional near infrared spectroscopy. Neuroscience \& Biobehavioral Reviews, 34(3), 269-284.

Loewenfeld, I. E. (1993). The pupil. Anatomy, physiology, and clinical applications.

Lohndorf, R. T., Vermeer, H. J., Cárcamo, R. A., De la Harpe, C., \& Mesman, J. (2019). Preschoolers' problem behavior, prosocial behavior, and language ability in a Latin-American context: The roles of child executive functions and socialization environments. Early Childhood Research Quarterly, 48, 36-49.

Malti, T., Gummerum, M., Ongley, S., Chaparro, M., Nola, M., \& Bae, N. Y. (2016). "Who is worthy of my generosity?" Recipient characteristics and the development of children's sharing. International Journal of Behavioral Development, 40(1), 31-40.

Margoni, F., \& Surian, L. (2018). Infants' evaluation of prosocial and antisocial agents: A meta-analysis. Developmental psychology, 54(8), 1445.

Marsh, A. A., Stoycos, S. A., Brethel-Haurwitz, K. M., Robinson, P., VanMeter, J. W., \& Cardinale, E. M. (2014). Neural and cognitive characteristics of extraordinary altruists. Proceedings of the National Academy of Sciences, 111(42), 15036-15041.

Meidenbauer, K. L., Cowell, J. M., Killen, M., \& Decety, J. (2018). A developmental neuroscience study of moral decision making regarding resource allocation. Child development, 89(4), 1177-1192.

Moreno, A. J., Klute, M. M., \& Robinson, J. L. (2008). Relational and individual resources as predictors of empathy in early childhood. Social Development, 17(3), 613-637.

Moss, J. (2012). Pictures and passions in the Timaeus and Philebus. In R. Barney, T. Brennan, \& C. Brittain (Eds.), Plato and the Divided Self (pp. 259-280). Cambridge: Cambridge University Press. doi:10.1017/CBO9780511977831.015

Murray, L., De Pascalis, L., Tomlinson, M., Vally, Z., Dadomo, H., MacLachlan, B., ... \& Cooper, P. J. (2016). Randomized controlled trial of a book-sharing intervention in a deprived South African community: effects on carer-infant interactions, and their relation to infant cognitive and socioemotional outcome. Journal of Child Psychology and Psychiatry, 57(12), 13701379.

Oakes, L. M. (2012). Advances in eye tracking in infancy research. Infancy, 17(1), 1-8.

Parchment, T. M., Small, L., Osuji, H., McKay, M., \& Bhana, A. (2016). Familial and contextual influences on children's prosocial behavior: South African caregivers as adult protective shields in enhancing child mental health. Global social welfare, 3(1), 1-10.

Paulus, M. (2014). The emergence of prosocial behavior: Why do infants and toddlers help, comfort, and share?. Child Development Perspectives, 8(2), 77-81.

Paulus, M., Kühn-Popp, N., Licata, M., Sodian, B., \& Meinhardt, J. (2013). Neural correlates of prosocial behavior in infancy: different neurophysiological mechanisms support the emergence of helping and comforting. Neuroimage, 66, 522-530.

Pedersen, C. A., Chang, S. W., \& Williams, C. L. (2014). Evolutionary perspectives on the role of oxytocin in human social behavior, social cognition and psychopathology. Brain research, 1580, 1.

Rajhans, P., Altvater-Mackensen, N., Vaish, A., \& Grossmann, T. (2016). Children's altruistic behavior in context: The role of emotional responsiveness and culture. Scientific reports, 6, 24089.

Rao, N., \& Stewart, S. M. (1999). Cultural influences on sharer and recipient behavior: Sharing in Chinese and Indian preschool children. Journal of Cross-Cultural Psychology, 30(2), 219-241.

Rivizzigno, A. S., Brendgen, M., Feng, B., Vitaro, F., Dionne, G., Tremblay, R. E., \& Boivin, M. (2014). Gene-environment interplay between number of friends and prosocial leadership behavior in children. Merrill-Palmer Quarterly (1982-), 60(2), $110-141$.

Rochat, P., Dias, M. D., Liping, G., Broesch, T., Passos-Ferreira, C., Winning, A., \& Berg, B. (2009). Fairness in distributive justice by 3-and 5-year-olds across seven cultures. Journal of Cross-Cultural Psychology, 40(3), 416-442.

Sabbagh, M. A., Xu, F., Carlson, S. M., Moses, L. J., \& Lee, K. (2006). The development of executive functioning and theory of mind: A comparison of Chinese and US preschoolers. Psychological science, 17(1), 74-81.

Safra, L., Tecu, T., Lambert, S., Sheskin, M., Baumard, N., \& Chevallier, C. (2016). Neighborhood deprivation negatively impacts children's prosocial behavior. Frontiers in psychology, 7, 1760.

Schmidt, M. F., \& Sommerville, J. A. (2011). Fairness expectations and altruistic sharing in 15-month-old human infants. PloS one, 6(10), e23223. 
Schuhmacher, N., Collard, J., \& Kärtner, J. (2017). The Differential role of parenting, peers, and temperament for explaining interindividual differences in 18-months-olds' comforting and helping. Infant Behavior and Development, 46, 124-134.

Sloane, S., Baillargeon, R., \& Premack, D. (2012). Do infants have a sense of fairness?. Psychological science, 23(2), 196-204. Steinbeis, N. (2018). Neurocognitive mechanisms of prosociality in childhood. Current opinion in psychology, 20, 30-34.

Stewart, S. M., \& McBride-Chang, C. (2000). Influences on children's sharing in a multicultural setting. Journal of CrossCultural Psychology, 31(3), 333-348.

Tomasello, M. (2000). Culture and cognitive development. Current Directions in Psychological Science, 9(2), 37-40.

Wainryb, C., \& Turiel, E. (1995). Diversity in social development: Between or within cultures. Morality in everyday life: Developmental perspectives, 283-316.

Warneken, F., \& Tomasello, M. (2007). Helping and cooperation at 14 months of age. Infancy, 11(3), 271-294.

Warrier, V., Toro, R., Chakrabarti, B., Litterman, N., Hinds, D., Bourgeron, T., \& Baron-Cohen, S. (2016). Genomewide analyses of empathy and systemizing: heritability and correlates with sex, education, and psychiatric risk. Cold Spring Harbor Labs Journals.

Wu, N., \& Su, Y. (2015). Oxytocin receptor gene relates to theory of mind and prosocial behavior in children. Journal of Cognition and Development, 16(2), 302-313.

Zaki, J., \& Ochsner, K. N. (2012). The neuroscience of empathy: progress, pitfalls and promise. Nature neuroscience, 15(5), 675. 